
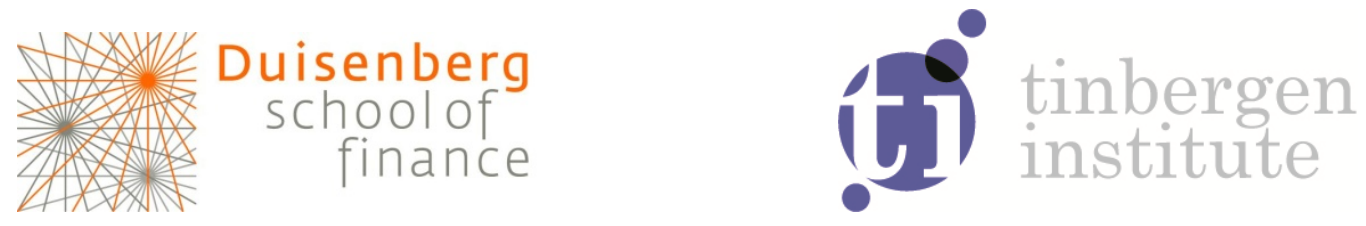

Duisenberg school of finance - Tinbergen Institute Discussion Paper

TI 13-126/VI/DSF 60

\title{
A Real Option Perspective on Valuing Gas Fields
}

Lin Zhao ${ }^{a, b, c}$ Sweder van Wijnbergena,b

a Faculty of Economics and Business, University of Amsterdam;

b Tinbergen Institute;

c Duisenberg School of Finance. 
Tinbergen Institute is the graduate school and research institute in economics of Erasmus University Rotterdam, the University of Amsterdam and VU University Amsterdam.

More TI discussion papers can be downloaded at http://www.tinbergen.nl

Tinbergen Institute has two locations:

Tinbergen Institute Amsterdam

Gustav Mahlerplein 117

1082 MS Amsterdam

The Netherlands

Tel.: +31(0)205251600

Tinbergen Institute Rotterdam

Burg. Oudlaan 50

3062 PA Rotterdam

The Netherlands

Tel.: +31(0)10 4088900

Fax: $+31(0) 104089031$

Duisenberg school of finance is a collaboration of the Dutch financial sector and universities, with the ambition to support innovative research and offer top quality academic education in core areas of finance.

DSF research papers can be downloaded at: http://www.dsf.nl/

Duisenberg school of finance

Gustav Mahlerplein 117

1082 MS Amsterdam

The Netherlands

Tel.: +31(0)20 5258579 


\title{
A Real Option Perspective on Valuing Gas Fields*
}

September 2, 2013

\author{
Lin Zhao ${ }^{a, b, c}$ \\ 1.zhao@uva.nl \\ and
}

Sweder van Wijnbergen ${ }^{a, b}$

s.j.g.vanwijnbergen@uva.nl

(a) University of Amsterdam
(b) Tinbergen Institute
(c) Duisenberg School of Finance

*Acknowledgement: We thank Prof. Ton Vorst for helpful discussions and comments. The authors gratefully acknowledge the financial support of EBN B.V., The Netherlands. 


\begin{abstract}
Real option theory has remained a fringe field; practitioners believe it is not practically applicable in complex real world environments. We show that this view is mistaken by applying real option theory to a highly complex energy problem with unhedgeable risk, time varying volatilities and endogenous exercise dates (non-European options). Investment decisions in the energy industry are often undertaken sequentially and are sensitive to information on markets and geographic conditions. Information may arrive gradually over time and as a consequence of early stage decisions. NPV-based frameworks are unsuitable because they do not allow for the fact that new information may change later stage decisions. We apply the approach to exploitation decisions for a Dutch cluster of gas fields, where gas prices and field reservoir size are the two main sources of uncertainty. Gas price returns show volatility clustering, which we model using a GARCH specification. Reservoir size uncertainty is unhedgeable, which necessitates an approach dealing with incomplete markets. Finally investment decisions can be postponed or delayed, which implies an non-European option setting, for which no analytical solutions exist. Correctly modeling the structure of volatility has a major impact: Option values shrink by $50 \%$ if the time varying nature of volatility is ignored. We also show that a high correlation between reservoir size at different locations creates large option values. The non-standard features of our approach have a major impact: option values are large so real options based valuations substantially exceed corresponding NPV calculations.
\end{abstract}

Keywords: real options, unhedgeable risks, volatility clustering, valuing American Options, gas field valuation, pricing flexibility

Classification-JEL: C61, G11, G31, G32, Q4

\title{
1 Introduction
}

Net Present Value (NPV) and Discounted Cash Flow (DCF) methods are widely used in capital budgeting processes. They are straightforward and convenient, but both methods ignore path-dependency ${ }^{1}$ embedded in projects and fail to incorporate the value of managerial flexibility to change or to revise decisions as new information becomes available. Real option analysis can be looked at as an extension of NPV, providing more accurate estimates of project values by taking both flexibility and path-dependence into consideration. This is of particular importance in the energy sector: investment decisions in the energy industry are

\footnotetext{
${ }^{1}$ Two projects are said to be path-dependent when one project can only be initiated upon completion of the other.
} 
often undertaken sequentially and are substantially influenced by new information on market conditions as well as on geographic conditions. During a year, a gas company routinely has to take all kind of day-to-day management decisions to which our analytical tools would apply:

- When to start exploration projects, like seismic programs or drilling exploration wells

- When to start development projects, like field development programs including development drilling, installing platforms and pipelines etc

- When/whether to apply enhanced production techniques like compression

- Abandonment decisions, like plugging wells and abandon and clean platforms and pipelines

Each decision is usually assessed by its stand alone parameters and value outcomes. However, in sequential investment projects where later investment opportunities are dependent on the outcome of earlier projects, starting early investments often brings in additional opportunities for further investments, which should be seen as an extra value of those early investments. Real option analysis is more appropriate in such circumstances than NPV as a decision tool in the capital budgeting process. But in practice, applications of real option theory have been limited to highly simplified investment decisions, modeled as simple option type problems. Anything approaching real world complexity is typically considered too difficult to solve using this approach. As a result, real option theory has remained something of a niche product, nice in theory but not useful for real world problems. In this paper, we show that such a view is mistaken: we provide a complex but trackable solution to much more complicated option style and strategic investment problems.

Real option analysis is often criticized for its misuse of standard option pricing models (i.e. the Black-Scholes formula) since the assumption of market completeness does not hold in most environments where it is or could be applied, which makes the preference free risk-neutral valuation methods underlying traditional option pricing formulas inapplicable. With regard 
to the application considered in this paper, there are two sources of risk associated with the value of underlying assets, market gas prices and reservoir volume. Gas contracts are traded on public markets so we can assume gas price uncertainty can be hedged; but investment projects also carry idiosyncratic risks, such as reservoir size, which cannot be hedged by appropriately structured replicating portfolios due to a lack of correlated traded instruments. This lack of market completeness makes standard option pricing methods inapplicable; we demonstrate two alternative approaches to solving the resulting valuation problems.

The value of embedded options is strongly influenced by the stochastic process of gas prices and reservoir distribution. Recent research in finance has shown that the second moment evolution of a price process should not be neglected. Therefore we use a GARCH model (Generalized Autoregressive Conditional Heteroskedasticity model, Engle, 1982; Bollerslev, 1986) for gas price returns incorporating clustering and heteroskedasticity in volatility. Based on econometric analysis we show that a GARCH model is the appropriate model for predicting the stochastic process of natural gas price returns and volatility. That structure turns out to have a major impact on option values. Reservoir size uncertainty is represented by a distribution derived from industry interviews. Although a few attempts have been made to predict commodity prices and volatility with GARCH models (e.g. Pindyck, 2003), this paper is to our knowledge the first application within a real option pricing framework. It also provides an empirical evidence of the effectiveness of a GARCH setting on option pricing problems.

The case study at hand, investment decisions in an offshore gas field, presents more nonstandard features. Because decisions can be brought forward or backward in time, the embedded options have endogenously determined exercise dates. We model the problem as a set of compound Bermuda options ${ }^{2}$. Solving this complex Bermuda style option pricing problem with multiple state variables is a formidable challenge because of spiraling dimensionality problems, which we bring down to manageable proportions through the use of simulation-based

\footnotetext{
${ }^{2} \mathrm{~A}$ Bermuda option is an option that can be exercised at a set of predetermined times.
} 
technique, Least Square Monte Carlo simulation (Longstaff and Schwartz, 2001).

We initially make the simplifying assumption of no reservoir size correlation among gas fields, but relax it later on in the analysis. To deal with the market incompleteness problem, we first use an approach based on ideas similar to the model method for incomplete markets, by setting a reasonable range of cost of capital. The cost of capital is the rate of return that capital could be expected to earn in an alternative investment with equivalent risk. The results yield a consistently higher project value than obtained through NPV, i.e. NPV consistently underestimates the project value. Sensitivity analysis of the option price relative to changes in the spot price of gas (i.e. Delta) shows that, as expected, option values are increasing in spot gas prices. So a higher spot price affects a project value through two channels, directly and indirectly, through its traditional NPV and option value respectively.

An alternative approach starts from the observation that if the assets on which options are written are not traded in public markets nor are the associated risks otherwise hedgeable, it is impossible to derive valuations that are preference free. This approach, utility indifference pricing for derivatives, makes the valuation an explicit function of the investor's degree of risk tolerance. We find that risk attitude has a significant influence on project valuation: option values are higher for investors with higher risk tolerance (lower risk aversion). Using this method we again find that option values increase substantially when we introduce correlation between reservoir sizes of different projects.

Finally, the compound option model analyzed and priced in this study can be easily reduced to a simpler model by leaving out the early or the late project. With appropriate modifications, it can be applied to valuing a wide variety of options that are different from the ones considered in this paper, for example options to wait, options to abandon projects, etc.

The remainder of the paper is organized as follows. Section 2 discusses a selected bibliography on real options including commodity prices modeling and option pricing methodology. Section 3 describes the general compound option problem we think appropriate to model our 
problem. Section 4 explains the methodology of gas pricing modeling and the GARCH option pricing model, as well as the introduction of a utility function necessary for the second valuation approach, utility indifference pricing. Section 5 provides the results of applying the framework to exploration decisions concerning a combination of offshore Dutch gas fields. Section 6 concludes.

\section{Literature Review}

\subsection{Real Option Analysis vs NPV}

Real Options Analysis is best seen as a complement rather than a substitute to traditional NPV calculations. ROA builds on NPV but allows for managerial response to new information coming on stream in the course of the project. The NPV scenarios are embedded in the analysis because a manager can always choose to adhere to NPV scenarios instead of switching between them. Dixit and Pindyck (1994) also stress that the differences between these two methods lie in the ability of ROA to incorporate and value flexibility and path-dependency among projects. As a consequence, an investment is always valued equally or higher by real option valuation than by NPV. In other words, NPV undervalues investments as long as there exists any possible flexibility. For instance, when evaluating mining plans under uncertainty, Dimitrakopoulos and Sabour (2007) shows the project value as valued by real option analysis is $11-18 \%$ higher than that by NPV. Quigg (1993) first presents empirical predictions of a real option-pricing model using a large sample of market real estate prices. She finds the wait to invest option accounts for a premium of $6 \%$ of the theoretical asset value; her analysis shows how option models help in understanding and predicting transactions prices over and above the intrinsic value. 


\subsection{Incomplete Market Setting}

In the gas field investment problem we focus on in this study, underlying asset value depends on two state variables, gas price and reservoir size. We assume that these variables are not correlated (Adam Borison, 2005); gas prices in the public market are obviously independent of the reservoir size of one small field, while with fixed extraction costs, the market developments also do not impact on the distribution of reservoir size ${ }^{3}$. Both reservoir uncertainty and our assumption of stochastic volatility introduce risk factors that are not directly related to any instrument traded in financial market. This makes it impossible to use traditional option valuation formulas; the replicating portfolios on which they are based do not exist.

The market incompleteness problem resulting from stochastic volatility is easier to deal with than the reservoir size related risk factor. Using a GARCH model to capture the stochastic volatility embedded in gas prices adds the second moment evolution of a price process. Duan (1995) provides a solution that approximates risk-neutral pricing to deal with the additional risk source brought by stochastic volatility.

The other risk factor resulting in market incompleteness is the unhedgeable risk caused by recoverable reserve size uncertainty. Hubalek and Schachermayer (2001) find that noarbitrage arguments yield no information on the option price in case of non-existence of a matching trading asset. They propose that an adjustment to the cost of capital should be made accordingly, which corresponds to our first cost-of-capital approach. Floroiu and Pelsser (2013) make a similar argument in a situation with model ambiguity. A more structured approach recognizes that in the absence of a replication portfolio it is not possible to achieve preference free valuation. Explicitly specifying the investor's risk preference leads to a utilitybased valuation method. An example of this approach is given by De Jong (2008), who also sees it as an appropriate approach for an incomplete market environment). Note that by assuming

\footnotetext{
${ }^{3}$ Recoverable reservoir size may be dependent on market gas prices if marginal extraction costs are increasing as more gas is extracted. We do not incorporate this dependence in our paper here, but it is an interesting extension and adds more managerial flexibility.
} 
a utility function with constant absolute risk aversion, we allow the investor to consider only the change of wealth brought by the corresponding investment instead of considering their total wealth.

Furthermore, a series of papers by Smith and Nau (1995), Smith (1996), Smith and McCardle (1998), and Smith and McCardle (1999) propose an integrated valuation procedure in real option analysis when markets are partially complete, a proposed modus operandi that we also follow. In practice this implies the following procedure. The underlying asset under concern here is separated into two parts. First, with the assumption of complete trading markets, unique risk-neutral probabilities for the market states can be determined. In our case of GARCH models, we approximate risk-netural pricing for gas detrivatives using Duan (1995). Second, subjective risk assessment of reservoir size is processed for project evaluation; and utility functions are introduced to capture an investor's risk preference. More specifically, the first step of this integrated method is to reduce a problem in incomplete market to an equivalent one in complete market, which is solved by valuing the effective certainty equivalent given a utility function of the decision maker.

\subsection{GARCH Option Pricing Model}

Most of the real option literature assumes that the price of underlying asset follows a Geometric Brownian Motion (GBM) process (McDonald and Siegel, 1986; Paddock, Siegel and

Smith, 1988), where commodity prices at any future time are lognormally distributed. But historical price return data shows strong volatility clustering, which contradicts the constant instantaneous volatility assumption used in traditional option analysis (Bates, 2003). Sadorsky (2006) finds that a single-equation GARCH model outperforms more sophisticated models in forecasting volatility of commodity returns. Hansen and Lunde (2005) obtain similar results, in terms of the ability to describe the conditional variance and forecasting ability, in their comparison of no less than 330 ARCH-type models. But a GARCH option pricing model is 
a function of the volatility risk premium embedded in the underlying asset, which invalidates the risk-neutral valuation relationship. An extension of the risk neutral valuation (so-called LRNVR, i.e locally risk-neutral valuation relationship) is explored by Duan (1995) to deal with the complex nature of $\operatorname{GARCH}(1,1)$ processes in option pricing. This property guarantees that the GARCH option pricing model is a well-specified model that at least locally does not depend on preferences. Two further conditions are required to satisfy LRNVR according to Duan (1995). With regard to our problem, these two conditions are

1. The investor is an expected utility maximizer and the utility function is time separable and additive; The utility function displaces constant absolute risk aversion;

2. Relative changes in the aggregate cash flow (NPV) are distributed normally with constant mean and variance under real measure $\mathbb{P}$.

We assume the investor maximizes a utility function satisfying the above conditions. Therefore LRNVR holds and our GARCH option pricing model is well specified. The LRNVR guarantees

the invariance of one-period ahead conditional variance with respect to a change in riskneutralized pricing measure.

Moreover, the time-varying volatility under $(\mathrm{G}) \mathrm{ARCH}$ processes results in solutions which are not analytically tractable, since the distribution of underlying asset prices cannot be derived in closed form even for European type options. So more advanced numerical techniques are needed, to which we turn in the following subsection.

\subsection{Least Square Monte Carlo Method}

The applied real option literature usually simplifies the kinds of projects encountered in practice by setting them up as simple European call/put options with fixed exercise dates (Smith and McCardle 1999, McDonald and Siegel 1986). This has the advantage that a closed form solution can be easily derived from the classical option pricing model such as the Black- 
Scholes formula (Black and Scholes, 1973). But firms run into much more complicated option problems in reality, involving not only path-dependence (Copeland and Tufano, 2004) and intercorrelation among investment projects, but also various risk sources. And managerial flexibility implies in most cases the possibility to postpone or accelerate investment decisions; this makes the real option problem more the equivalent of an American (or, in discrete time, a Bermuda) option with endogenous exercise dates rather than a European option with one fixed exercise date.

By rephrasing the investment problem as a dynamic programming problem, the decision maker at each exercise date considers a two-step optimal strategy. The first step is to compare immediate exercise payoff with the expected payoff of continuing (waiting) and possibly exercising later; and next, the decision maker chooses not to exercise the option now if waiting is more valuable than exercising now. The next exercise date, the same structure of choice presents itself again. The choice of exercise dates and the calculation of continuation payoffs both become even more complicated in the case of compound options, because values of unlocked options further in the future should also be taken into consideration in calculating continuation values now.

Without a closed form solution, advanced numerical techniques are required to solve the resulting dynamic programming problem. Lattice methods (Cox et al. 1979, Trigeorgis 1996) are simple from a computational point of view and do not require closed-form solutions. However, despite their flexibility and ease of application in valuing projects with many embedded options, lattice techniques suffer from dimensionality difficulties and are therefore in practice unable to handle multidimensional problems of a significant size.

Longstaff and Schwartz (2000) propose a simulation-based technique instead. Similar to Carr and Yang (1998), this Least Square Monte Carlo (LSMC) method is able to value various styles of options including American options or more exotic options and to manage multiple uncertainties described by complex stochastic processes without sacrificing option pricing 
tractability. It approximates conditional continuation values with linear regression results derived from backward simulation results. The backward simulations form the basis of the regressions linking continuation values to state variables; although the backward simulations cannot be used in the valuation exercise, the regression functions can be used in a subsequent forward simulation study to approximate continuation values. It essentially solves the dimensionality problem, the complexity now increases linearly in dimension size instead of exponentially.

Moreover, this algorithm is not restricted to Markovian processes; similar algorithms can easily be applied to non-Markovian processes, like the $(\mathrm{G}) \mathrm{ARCH}$ process we use. See for example Stentoft (2005), who applies the LSMC method to price options with early exercise features within a GARCH context. Of relevance to our study is the conclusion reached by Stentoft (2005) based on his empirical analysis of out-of-sample performance, that GARCH effects are of substantial importance and lead to significant improvements over constant volatility model results.

\section{Problem Description}

Drilling for near-field prospective resources is appealing because it both reduces unit operating cost and extends infrastructure life as many viable prospects are located outside platform owner's acreages. More accurate estimates of reservoir sizes of near fields can be obtained through accessing the information of first drilling. Thereafter an option problem rises. Here we simplify an investment problem as follows.

Figure 1 illustrates a compound real option problem concerning both Prospect A and Prospect $\mathrm{B}^{4}$, where the Platform, main pipeline, and Pipeline $\mathrm{C}$ for transportation are previously constructed infrastructure. Prospect A and Prospect B are both prospective gas fields

\footnotetext{
${ }^{4}$ Here a prospect is defined as a gas field where recoverable reserves have been identified by initial exploration.
} 
Figure 1: A Schematic Layout of a Simplified Problem

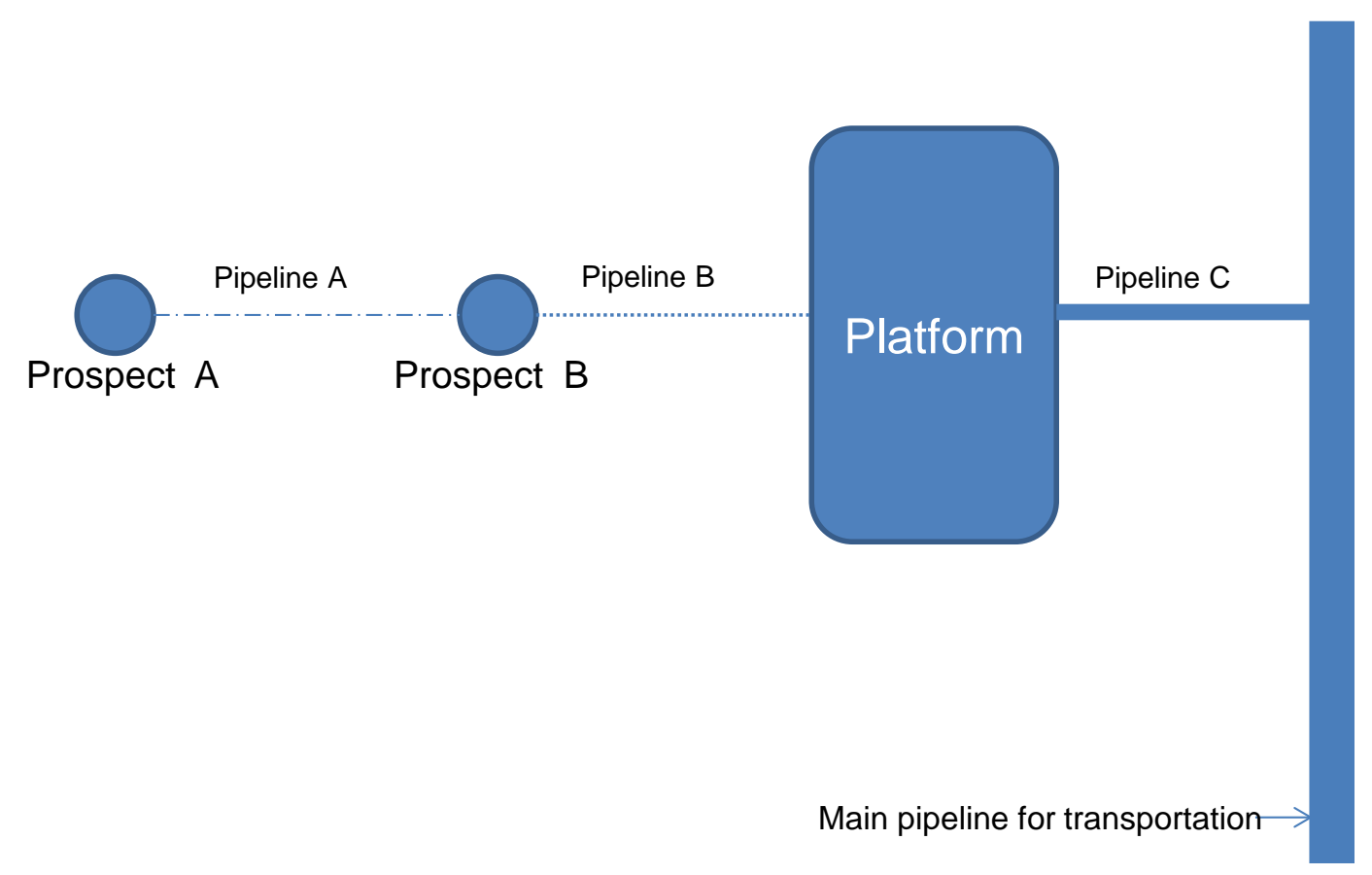


sharing similar geologic and geographic properties, and the dash lines represent pipelines to be built for developing A or B.

The reservoir uncertainty of Prospect B can be resolved after one-year production, which, due to similar geological structure, will provide information on the reserve distribution of Prospect A. Based on new information, the firm continues to decide whether and when to explore Prospect A. Moreover, higher gas prices also make new investment projects more attractive. For instance, if the gas price turns out to drop dramatically after one year, the decision maker can simply choose to delay or abandon further investment if reservoir size of A is proved to be poor.

To summarize, under the schematic layout, the investor's problem can be written as a combination of two options. The first option is when/whether to start developing B: when/whether to exercise the waiting option on B. The second option is subject to the exercise of the first one. Once the waiting option of B is exercised, the firm holds the right to decide whether and when to exercise the option to undertake project A. So the two combined form a compound option problem. The underlying asset of the option problem depend on market gas price and reservoir distribution. Our aim is to evaluate prospect B by taking both fixed cash flows and future opportunities into consideration, i.e. an extra option value is added to the project evaluation on top of the traditional NPV method, where this extra option value also depends on the profitability of Prospect A.

\subsection{Reservoir Distribution}

In conformity with industrial standard terminologies, the reservoir distribution of a gas field is decomposed into probability of success (POS) and reservoir size $R$. As is shown in Figure 2a, reservoir amount $R>0$ is found with a probability equal to POS; otherwise zero reserve amount is recovered with probability of 1-POS. Moreover, reservoir size $R$ is random and follows a mixed distribution as illustrated in Figure $2 \mathrm{~b}$. The distribution function of $R$ consists 
of three atoms, where atom P50 has a probability mass of 40\%, atom P10 and P90 each has a probability mass of $30 \%$. Here P90 stands for the most pessimistic reservoir, meaning that the probability of a real production would be better than P90 case is $90 \%$. On the same analogy, P10 case is the most optimistic reservoir estimation that can only be accomplished with a low probability of $10 \%$. During the project evaluation process, production profiles which may differ in both production lifetime and amounts are designed separately based on three scenarios. For instance, in our case, the production lifetime of P90 and P50 is four years, while for the high case P10, the active period is five years. Moreover, we can easily calculate its mean as mean $=0.3 \times P 90+0.4 \times P 50+0.3 \times P 10$. 
Figure 2: Distribution of Reservoir Size

(a) Distribution of Reservoir Size

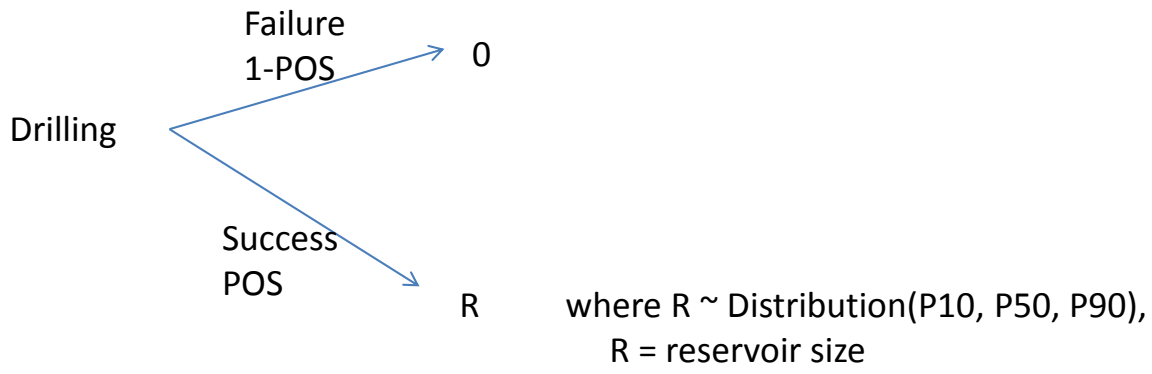

(b) Cumulative Distribution and Probability Distribution for Reservoir Size in Case of Success
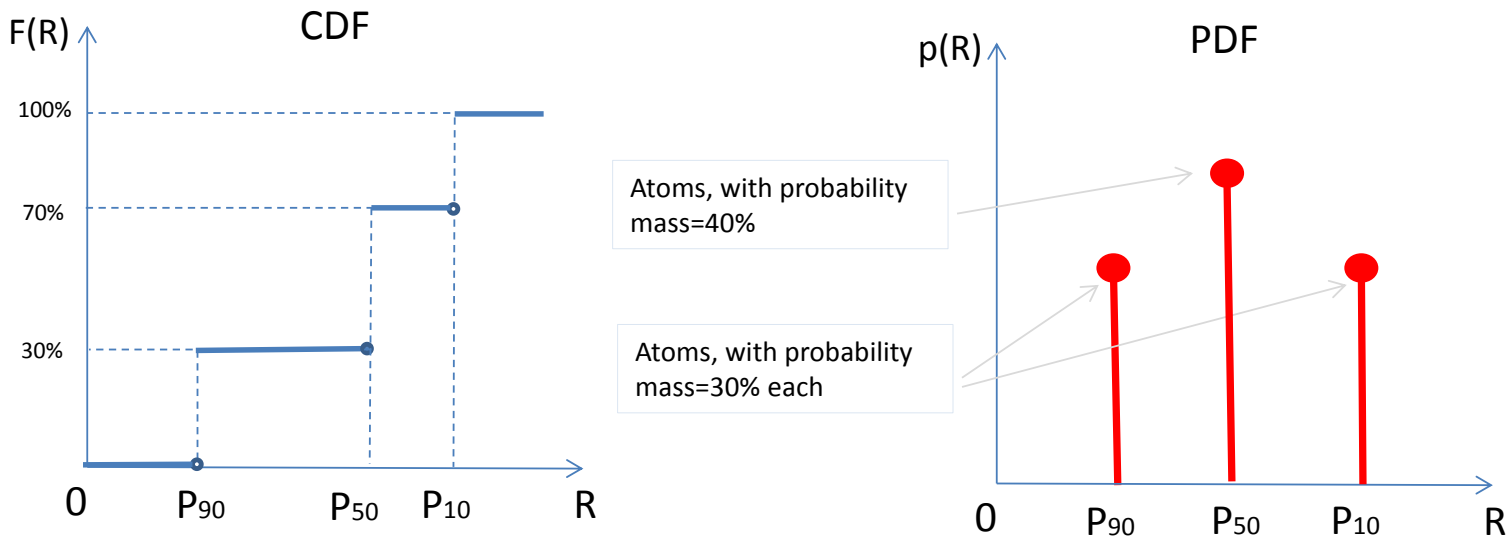

Atom: Given a measurable space $(X, \Sigma)$ and a measure $\mu$ on that space, a set $A$ in $\Sigma$ is called an atom if $\mu(A)>0$ and for any measurable subset $B$ of $A$ with $\mu(A)>\mu(B)$, one has $\mu(B)=0$.

In the application followed up, we first investigate a simplified case where the reservoir distribution of A and B are uncorrelated. Additionally, we assume the cumulative distribution of reservoir amount conditional on successful drilling (i.e. $R$ ) remains unaffected, but these two reservoirs are correlated knowing that a successful drilling of Prospect B results in a higher POS of Prospect A. 


\subsection{Option Model Set-up}

Figure 3 shows the timeline of the investment problem. $T$ is the minimum license duration of Prospect A, B, and their facilities; $T_{A}$ and $T_{B}$ are production periods of Prospect $\mathrm{A}$ and $\mathrm{B}$ respectively; $t_{A}$ and $t_{B}$ are the production starting dates of $\mathrm{A}$ and $\mathrm{B}$. Interval $\mathrm{I}$ contains all possible starting points of Project B; and Interval II contains all possible starting points of Project A, whose lower boundary is subject to the starting date of project B, i.e. $t_{B}$.

Figure 3: Timeline of Investment

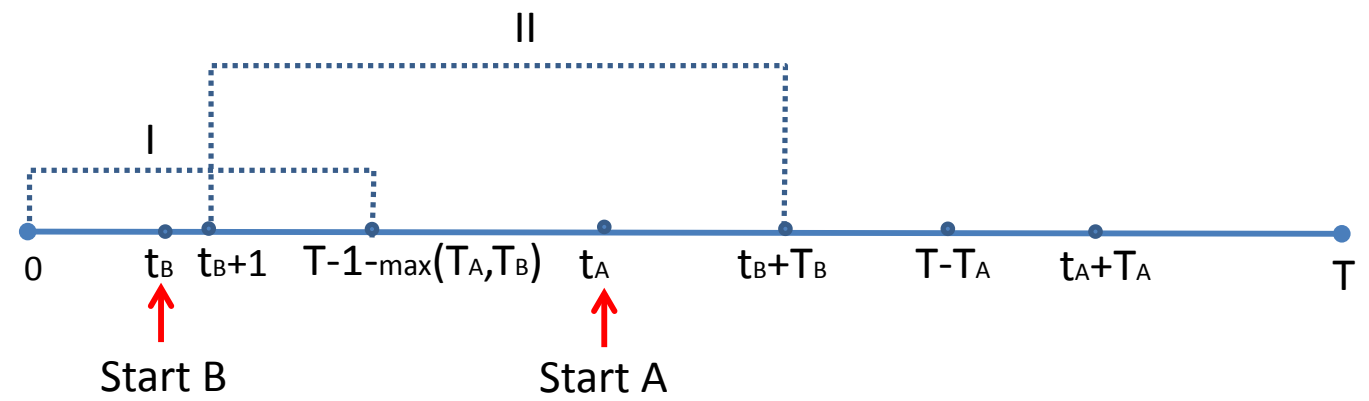

We construct two sequential Bermuda-style options, which can be exercised at a set of predetermined dates before maturity. The first option is a waiting option on Prospect B starting from time 0 with maturity $T-1-\max \left(T_{A}, T_{B}\right)$. Investor has the option to wait until the market gas price increases so that higher profits are realized. Once the waiting option is exercised $^{5}$ at time $t_{B}$ and further information on POS (or $R$, or both) of $\mathrm{A}$ is gained at time $t_{B}+1$, the firm decides whether and when to explore Prospect A by taking both reservoir size and future gas prices into consideration. The project A option arises after one-year production of $\mathrm{B}\left(\right.$ i.e. $\left.t_{B}+1\right)$, when the reservoir quantity of $\mathrm{B}$ is revealed. It has a maturity $T_{B}-1$ with the assumption that the second option disappears once the development of Prospect B is finished; so we have $t_{A} \in I I \equiv\left[t_{B}+1, t_{B}+T_{B}\right]$. Since B unlocks option A, the project value of B

\footnotetext{
${ }^{5}$ i.e. the firm starts drilling at Prospect B.
} 
should include the value of managerial flexibility embedded in project A.

\section{Methodology}

\subsection{Predicting Future Gas Prices}

\subsubsection{Gas Price Data}

The Dutch gas market has been considered as a mature and stable trading market on the continent especially since the Title Transfer Facility (TTF) was set up in 2003. Operated by TSO GTS, a wholly owned subsidiary of Gasunie, the TTF virtual hub is the second largest European OTC gas trading market in terms of trading volumes and number of trades. It is also the virtual gas hub covering all high calorific entry and exit points in the Netherlands.

TTF records volume-weighted average natural gas price (Euro/Megawatt Hour) of all orders that are executed and delivered on the same day. A weekly spot data set with 365 observations was obtained from Datastream covering the period of Mar 7, 2005 through May 18, 2012, where the starting date was constrained by the beginning of data available on Datastream. Descriptions are given in Table 1.

Table 1: Statistics of Weekly Spot Prices

\begin{tabular}{c|cccccc}
\hline Statistics & Observations & Mean & Std. Dev. & Variance & Skewness & Kurtosis \\
\hline \hline Spot Prices & 365 & 18.7072 & 5.6142 & 31.5197 & -0.0495 & 2.3026 \\
\hline
\end{tabular}

Phillips-Perron unit root test and Dickey-Fuller unit root test were used to detect the existence of unit roots in historical gas data (test results in Appendix). The test results show that time series $P_{t}$ or $\ln P_{t}$ has a unit root while first difference of gas prices $\Delta P_{t}$, or first difference of $\log$ prices $\Delta \ln P_{t}$ are both stationary time series with p-value 0.0000 . Only stochastic trend exists in this time series. By observing Figure 4b, the log price returns series 
moves with gradual upward and downward fluctuations around a long-term mean. We continue investigating the properties of logarithm return time series since its first difference series is stationary and contains no trend. Figure 4b suggests changes in variance; there is evidence of volatility clustering. For instance, larger fluctuations during the periods 2005-2006 and 2009-2010 are followed by less volatile periods.

Figure 4: Spot Price and Log Price Returns

(a) Weekly Spot Prices

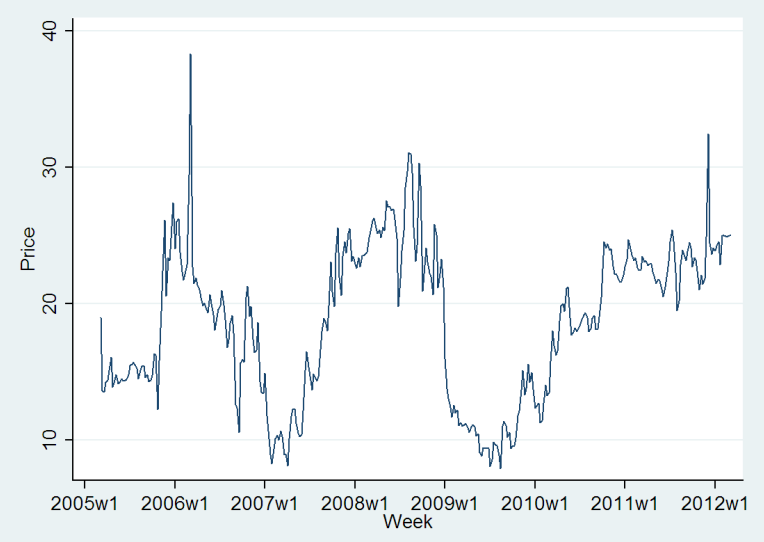

(b) Log Price Returns

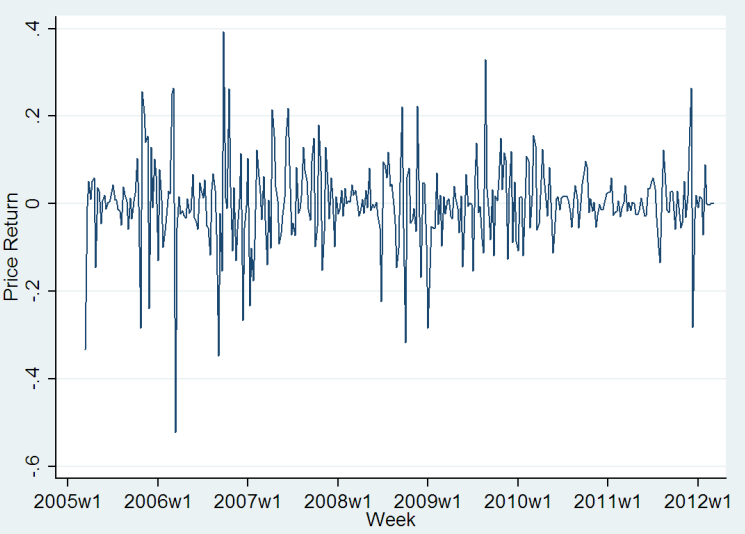

\subsubsection{GARCH Model Estimation}

Due to techniques such as hydraulic fracturing, or "fracking", gas development costs in US have been dramatically driven down since shale gas extraction became economically viable. However this technique is still controversial in Europe and therefore has not been applied on a large scale yet. So we expect no structural change for the foreseeable future.

Let $P_{t}$ be the spot gas price at time $t$. Suppose under probability measure $\mathbb{P}$, its one-period rate of return has conditionally lognormal distribution. Following Duan (1995), we have 


$$
\begin{aligned}
\ln \frac{P_{t}}{P_{t-1}} & =\mu+\lambda \sqrt{h_{t}}-\frac{1}{2} h_{t}+\tilde{\varepsilon}_{t}, \\
h_{t} & =\alpha_{0}+\alpha_{1} \tilde{\varepsilon}_{t-1}^{2}+\alpha_{2} h_{t-1}, \\
\text { where } & \tilde{\varepsilon}_{t} \mid \mathscr{F}_{t-1} \sim N\left(0, h_{t}\right)
\end{aligned}
$$

where $\mu$ is constant one-period risk-free rate of return and $\lambda$ is the constant unit risk premium.

Here, $\mathscr{F}_{t-1}$ is the information set, up to and including time $t-1 ; \alpha_{1}, \alpha_{2} \geq 0$ so that non-negative variance is guaranteed. To ensure its stationarity, $\alpha_{1}$ and $\alpha_{2}$ need to satisfy $\alpha_{1}+\alpha_{2}<1$. The process $\tilde{\varepsilon}_{t}^{2}$ follows an $\operatorname{ARMA}(1,1)$ process.

\subsubsection{GARCH Option Pricing Model}

Duan (1995) shows that under risk-neutral pricing measure $\mathbb{Q}, \ln \frac{P_{t}}{P_{t-1}}$ follows a normal distribution conditional on $\mathscr{F}_{t-1}$ under assumptions mentioned in 2.3 and that

$$
\operatorname{Var}^{\mathbb{P}}\left[\ln \frac{P_{t}}{P_{t-1}} \mid \mathscr{F}_{t-1}\right]=\operatorname{Var}^{\mathbb{Q}}\left[\ln \frac{P_{t}}{P_{t-1}} \mid \mathscr{F}_{t-1}\right]
$$

Hence under the risk neutral measure $\mathbb{Q}$, the LRNVR is sufficient to reduce all preference considerations and it implies the logarithm return follows a stochastic process as

$$
\begin{aligned}
\ln \frac{P_{t}}{P_{t-1}}= & \mu-\frac{1}{2} h_{t}+\varepsilon_{t}, \\
h_{t}= & \alpha_{0}+\alpha_{1}\left(\varepsilon_{t-1}-\lambda \sqrt{h_{t}}\right)^{2}+\alpha_{2} h_{t-1}, \\
\text { where } \quad & \varepsilon_{t} \mid \mathscr{F}_{t-1} \sim N\left(0, h_{t}\right) .
\end{aligned}
$$

where annual risk-free return is $3 \%$.

A MA(2)-GARCH(1,1) model is selected for predicting returns and volatilities of future 
gas prices.

$$
\left.\begin{array}{rl}
\ln \frac{P_{t}}{P_{t-1}}= & 0.00058-\frac{1}{2} h_{t}+\varepsilon_{t}+0.114 \varepsilon_{t-1}-0.178 \varepsilon_{t-2}, \\
(-0.095) \quad(-0.072)
\end{array}\right)
$$

Model comparisons and diagnostic tests are presented in Appendix B.

\subsection{Integrated Valuation Method}

Given a complete market, we value a claim $O P$ by replicating it with the unique self-financing portfolio, which yields a price $X_{T}$ at the final date $T$. Therefore $X_{0}$ gives the price of $O P$ at time 0 . However, a claim in an incomplete market cannot be perfectly replicated and we run into a problem of finding a unique price for this claim. More specifically, selling such a claim entails exposing oneself to an idiosyncratic/unhedgeable risk, which can be represented by $X_{T}-O P\left(\right.$ or $\left.O P-X_{T}\right)$ at time T. This difference can be solved by specifying the investor's preference towards the risk. Therefore the price of the claim should be

$$
O P_{0}=X_{0}+\text { utility value of }\left(O P_{T}-X_{T}\right)
$$

which results in the failure of preference free pricing. This leads to the necessity of introducing utility function to capture individual's preference.

Assume the investor has a utility function which is additive among individual periods such that the firm's utility at time 0 equals the sum of the utility of discounted cash flow over all 
periods. We assume the investor's preferences exhibit constant absolute risk aversion (CARA):

$$
u_{t}\left(x_{t}\right)=-\exp \left(-x_{t} / \rho_{t}\right)
$$

where $\rho_{t}>0$ represents the decision maker's period-t risk tolerance. This assumption of utility function implies that the investor's behavior does not depend on his initial wealth, and he only cares about the change of his wealth caused by an investment. These two assumptions (additivity and CARA) imply a certainty equivalence expression:

$$
\exp \left(-\tilde{x}_{t}^{C E} / \rho_{t}\right)=\mathbb{E}_{t}\left[\exp \left(-\tilde{x}_{t} / \rho_{t}\right)\right]
$$

with

$$
\tilde{x}_{t}^{C E}=-\rho_{t} \ln \left(\mathbb{E}_{t}\left[\exp \left(-\tilde{x}_{t} / \rho_{t}\right)\right]\right)
$$

with $\tilde{x}_{t}$ as an uncertain cash flow at period-t.

Suppose a project has a series of future cash flows $\left\{C F_{0}, C F_{1}, \ldots, C F_{T}\right\}$ where $C F_{t}=$ $P_{t} \times G_{t}-C_{t}$, with gas price $P_{t}$, production $G_{t}$, and cost $C_{t}$ at time $t$. More generally, we have $v_{t}=N P V_{t}\left(P_{t}, R_{t}, u_{t}\right)= \begin{cases}0 & \text { if } u_{t}=0, \text { i.e. no exercise } \\ \mathbb{E}_{t}\left(P O S \times \sum_{i=t}^{T+t} e^{-(i-t) r_{f}}\left(P_{i} \times G_{i}-C_{i}\right) \mid P_{t}, R_{t}\right) & \text { if } u_{t}=1, \text { i.e. exercise }\end{cases}$

where $R_{t}$ is the realized reservoir volume; and $u_{t}$ is a dummy variable, representing the decision to exercise.

Effective certainty equivalent is represented as $E C E_{t+1}(\cdot)$, defined by taking expectations over period-t's private uncertainties (reservoir) conditional on the outcome of period-t's market uncertainties (gas market). The calculation of $E C E_{t+1}(\cdot)$ depends on assumptions of the utility function. For instance, an exponential utility function with an effective risk tolerance equal to the sum of the decision maker's discounted future risk tolerance leads to 


$$
E C E_{t+1}\left[v_{t+1} \mid \mathscr{F}_{t+1}^{m}, \mathscr{F}_{t}\right]=-\gamma_{t+1} \ln \left(\mathbb{E}_{t}\left[e^{-\frac{v_{t+1}}{\gamma_{t+1}}} v_{t+1} \mid \mathscr{F}_{t+1}^{m}, \mathscr{F}_{t}\right]\right)
$$

Here $v_{t}$ denotes the project value at time $t$ and $\gamma_{t}=\sum_{\tau=t}^{T} \frac{\rho_{\tau}}{\left(1+r_{f}\right)^{\tau-t}}$ is the NPV of the future period risk tolerances, where $\rho_{t}$, same as before, denotes the decision maker's period-t risk tolerance. Therefore the integrated valuation approach uses effective certainty equivalent instead of NPV as an proxy of project value. Note that if $\gamma \rightarrow+\infty$, this decision make becomes risk neutral and the option pricing problem becomes identical as if one in complete market.

\section{Application}

In this section, we apply the proposed model to a Dutch offshore case in Netherlands, where two prospects are distributed as shown in Figure 1. Evaluated separately from Prospect B, Prospect A has a possibly large reserve quantity but conditional on a low probability of successful drilling; furthermore, initial explorations prove a poor reservoir potential of Prospect B. Knowing that the cost of initial exploration can be considered as sunk costs which can never be recovered, the investor needs to decide whether to abandon Prospect $\mathrm{B}$ or to continue developing it with its POS equal to $80 \%$. Here the maturity of the option on starting B is defined as the closest license duration of Prospect B, Prospect A and other facilities, and its exercise time is at the end of every following year. Unlike B, which has a high POS after thorough exploration procedures, Prospect A has a much smaller POS of $30 \%$. The tradeoff embedded in the problem is that Prospect B in itself is not economically attractive enough for the firm, but giving up B effectively blocks future investment opportunity of A. However if B would turn out to be a failure, A would lose investor's interests too. The decision tree is shown in Figure 5. 
Figure 5: Decision Tree

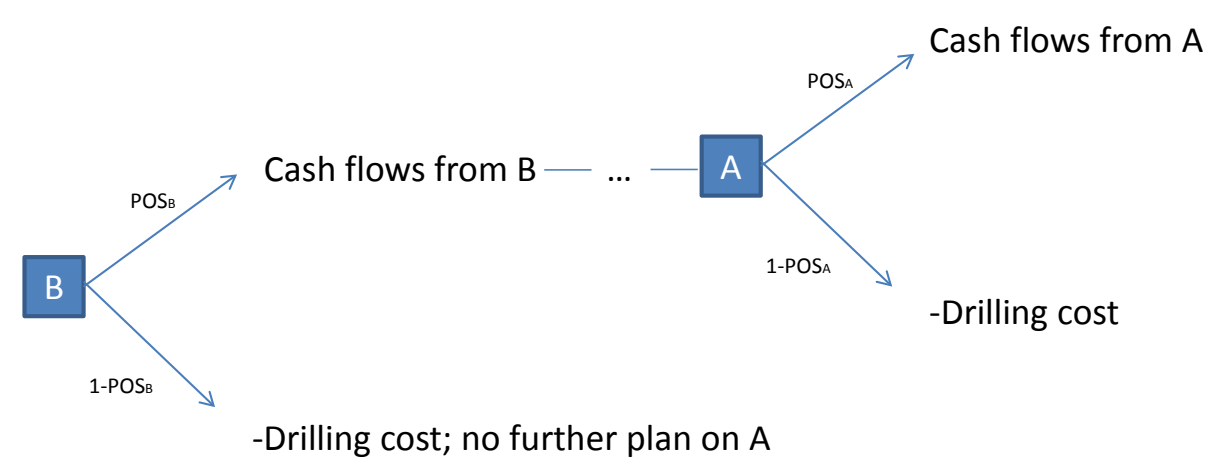

For both methods of Cost-of-capital and integrated valuation, we first consider a simple case where the revealed reservoir quantity of $\mathrm{B}$ adds no further information on $\mathrm{A}$ and then a complicated one when further updates based on the outcome of B are possible. Moreover, results and empirical tests on the properties of option values are also conducted under both methods.

\subsection{Cost-of-Capital Method}

We choose a reasonable range for cost of capital ${ }^{6}$ that reveals the underlying risk of a project. The dotted line in Figure 6 exhibits the simulated NPVs of Prospect B with respect to a range of cost of capital (from 3\% to 15\%), where the red horizontal line separates projects with positive and negative NPVs. It is clear that due to its low NPV, Prospect B is not economically attractive enough to be developed in itself. Even if the manager chooses projects only based on the sign of NPV, Prospect B is still rejected if the cost of capital is higher than $12 \%$.

\footnotetext{
${ }^{6}$ The range includes all cost of capitals being used for the firm's budgeting process.
} 


\subsubsection{Results without reservoir information update}

Option values are calculated for cost of capital rates varying from $3 \%$ to $15 \%$, with risk-free rate equal to $3 \%$. Figure 6 shows that the integrated value of Prospect B is greatly increased when option values are taken into consideration. For instance, with a cost of capital equal to the risk free rate $(3 \%)$, we assume the risk of the underlying asset can be perfectly hedged in the market. The simulated NPV of Prospect B is then $€ 1.53 \mathrm{mln}$. But its corresponding option value is $€ 19.47 \mathrm{mln}$, resulting in an integrated value of $€ 20.99 \mathrm{mln}$. However, one has completely ignored the risk embedded in reservoir by using the risk-free rate as the cost of capital. To take the reservoir risk into consideration, we effectively assume the reservoir risk is captured by subtracting the risk-free rate from the cost-of-capital; therefore the cost-of-capital is presumably reflects risk preferences and serves as a solution to deal with the incomplete market problem.

Take another example when the cost of capital is $15 \%$. The negative NPV of Prospect B $(€-1.50 \mathrm{mln})$ results in a rejection of this project based on the traditional selection criterion. While real option analysis gives a positive integrated project value of $B(€ 8.70 \mathrm{mln})$ implying its commercial profitability; as a result it leads to an opposite investment decision to one made under traditional NPV. 
Figure 6: Option Values vs NPV

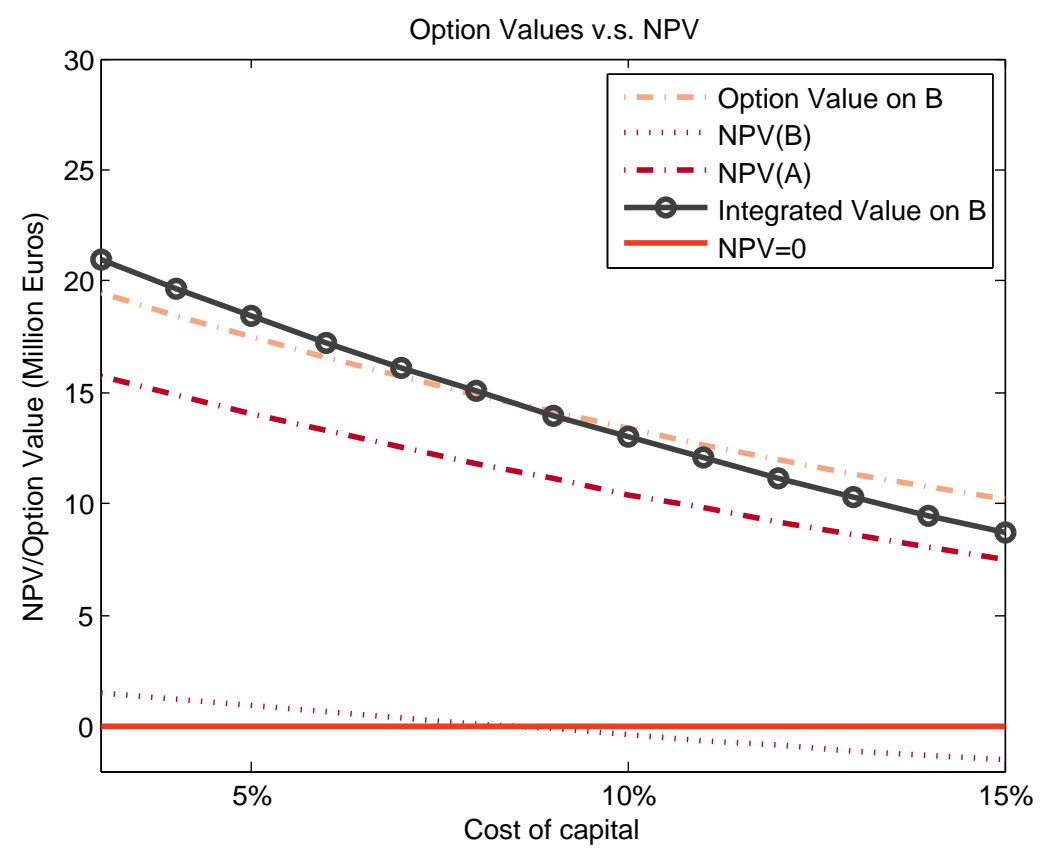

Integrated Value on $\mathrm{B}=\mathrm{NPV}$ of $\mathrm{B}+$ Option Value on $\mathrm{B}$.

Therefore real option valuation plays a crucial role in investment decisions by accepting projects that could have been rejected under traditional evaluation rules. Under real option valuation, the prospect $B$ is valuable for development under all cost of capital considered. As a result, the firm should not simply abandon Prospect B; in fact, with the further exploration opportunity on A, the project yields a positive expected value and is worth investing. Furthermore, given the more precise evaluation of the projects, the firm can compare them with other investment opportunities and then choose (one of) those with highest values.

Two observations from Figure 6 are also worth commenting. First, as a natural result, Project A is less valued with higher cost of capital rates. Therefore as expected, the option value decreases in discount rates as well due to the shrinking value of Project A.

Second, note that the declining option value does not imply a negative Greek $\rho$, which is 
defined as an sensitivity measure evaluating the sensitivity of option value to the risk-free rate: it is the derivative of the option value with respect to the risk free interest rate. Risk-free rate here remains unchanged. What is shown in Figure 6 is the interaction between option value and cost of capital, where cost of capital is used to adjust payoffs.

\subsubsection{GARCH Model vs Constant Volatility}

Due to the limited downside of options, an option becomes more valuable as the volatility of underlying assets increases. Thus precise structure of volatility process is important in valuing options. This subsection discusses how option value changes along with alternative variance modeling.

Suppose the logarithm price return time series follows a log-normal distribution with mean and constant variance calculated from the same TTF data set as used for the above GARCH model. Following the same analogy, we show option values of the offshore case in Figure 7.

In comparison to 5.1.1, the real option value is still positive but is only half size as the result under GARCH model (Figure 6). Thus, neglecting clustered volatility dramatically undervalues the corresponding options. Now the simulated NPV of B is negative under all cost of capital rates considered. Both option values and NPVs are significantly underestimated and the project is more likely to be rejected under constant volatility assumption. Failure to capture the main characteristic of volatility leads to severely biased results ${ }^{7}$. This finding is also consistent with standard finance option pricing theories where higher uncertainty results in higher option values.

\footnotetext{
${ }^{7}$ The reason why the results of different gas price modelings differ so much is that, we are modeling log price return instead of gas price itself. Therefore a slight change in log price return may result in a large change in gas price prediction, which has a significant influence on option values.
} 
Figure 7: Option Values vs NPV with constant variance

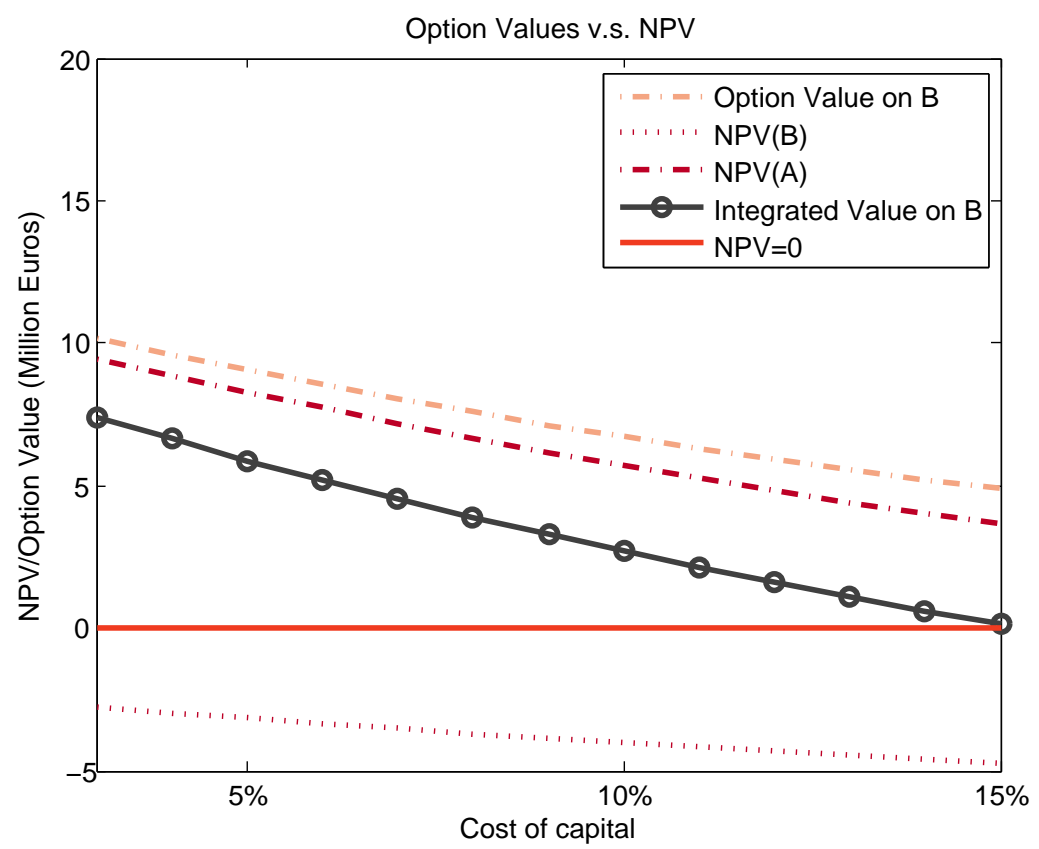

\subsubsection{Spot Prices vs Option Values}

Figure 8 shows how the integrated value and option value of Prospect $B$ change with spot prices, i.e. Delta. It can be observed from both $2 \mathrm{D}$ and $3 \mathrm{D}$ plots in Figure 8 that option values are increasing in spot prices. This means that given a high spot price on the market, the firm is more likely to accept a project if it takes option value into account. On the other hand, similar as what we have found before, the option value decreases as the cost of capital grows. In other words, Delta is decreasing in cost of capital.

\subsubsection{Results with reservoir information update}

Until now we considered the case without reservoir correlation and that the option problem is an issue caused only by the dynamics of future gas prices. In this section, we introduce one 


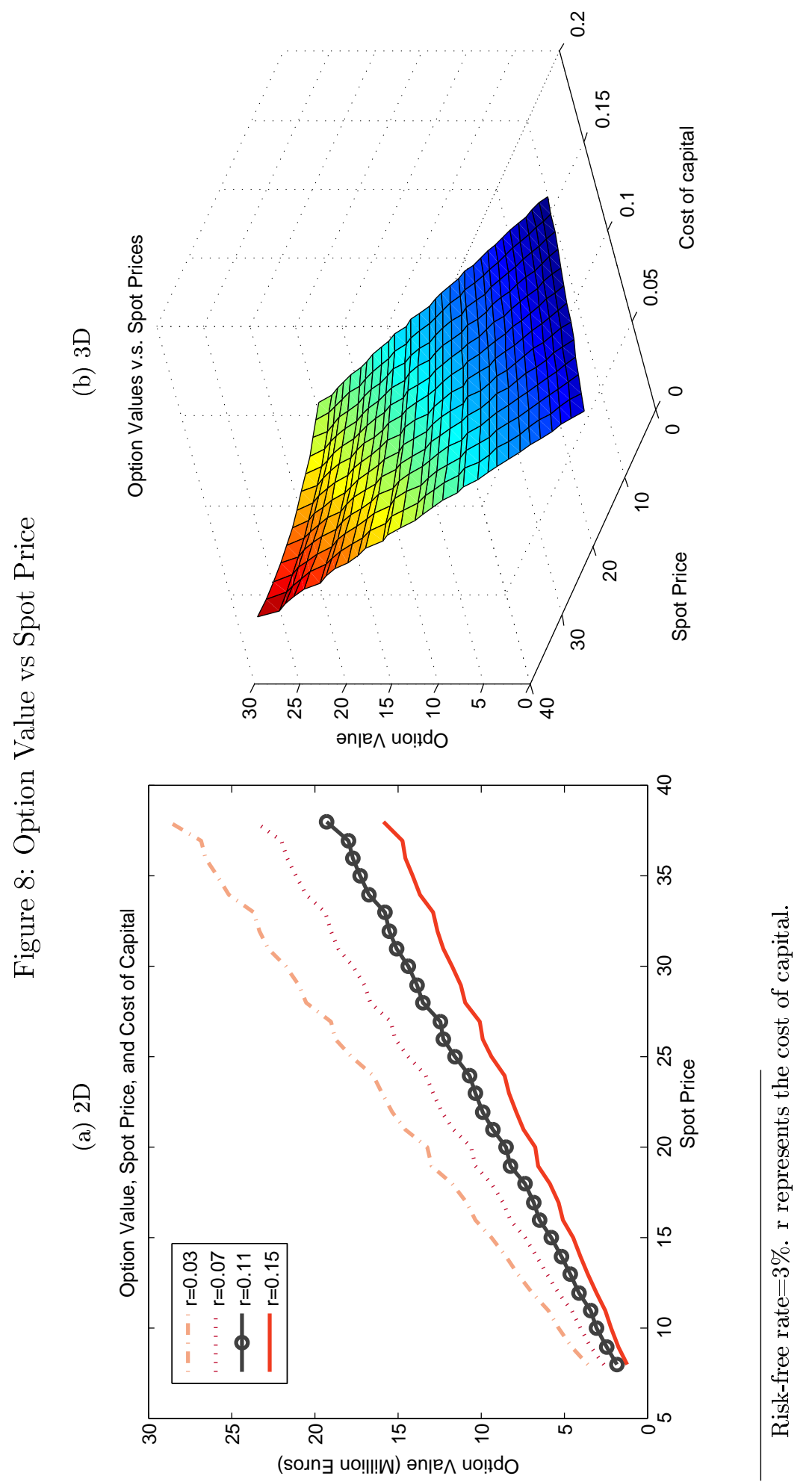


extra dimension to our model by taking reservoir correlation into consideration. For practical reasons, given the structure of uncertainty we work with, we can distinguish three cases of correlation. The first one considers that only POS of A and POS of B are correlated. Assume that $\mathrm{POS}$ of $\mathrm{A}$ rises to $50 \%$ given a success drilling of $\mathrm{B}$. The second case considers when POS remains unchanged but focuses on correlation between the PDFs of reservoir (i.e. $R$ ) in particular. We assume that if the reservoir size of B turns out to be equal to that of P10 case, then the reservoir size of A equals the outcome of its P10 case as well. Similarly, a P50 (P90) outcome of B also implies a P50 (P90) outcome of A. Lastly, Case III combines the first two cases, where both information updates in POS and R are considered. Note that the three cases can be reduced to only one if an alternative reservoir distribution is assumed with POS and $\mathrm{R}$ mingled together.

Figure 9 presents all the results from the three cases as well as the one with no correlation. For all three cases with correlation, option values are much larger than what is obtained without reservoir correlation. This is an obvious result because the more information can be gained in the future, the more valuable the option is. In addition, the option value of Case III is larger than either option value in Case I or in Case II. This is to be expected since information has been updated to the largest extent in Case III. The positive correlation between option price and reservoir correlation is consistent with the intuition that the option is more valuable when more information of the underlying assets can be acknowledged in the future. 
Figure 9: Cost-of-capital method with Reservoir Correlation

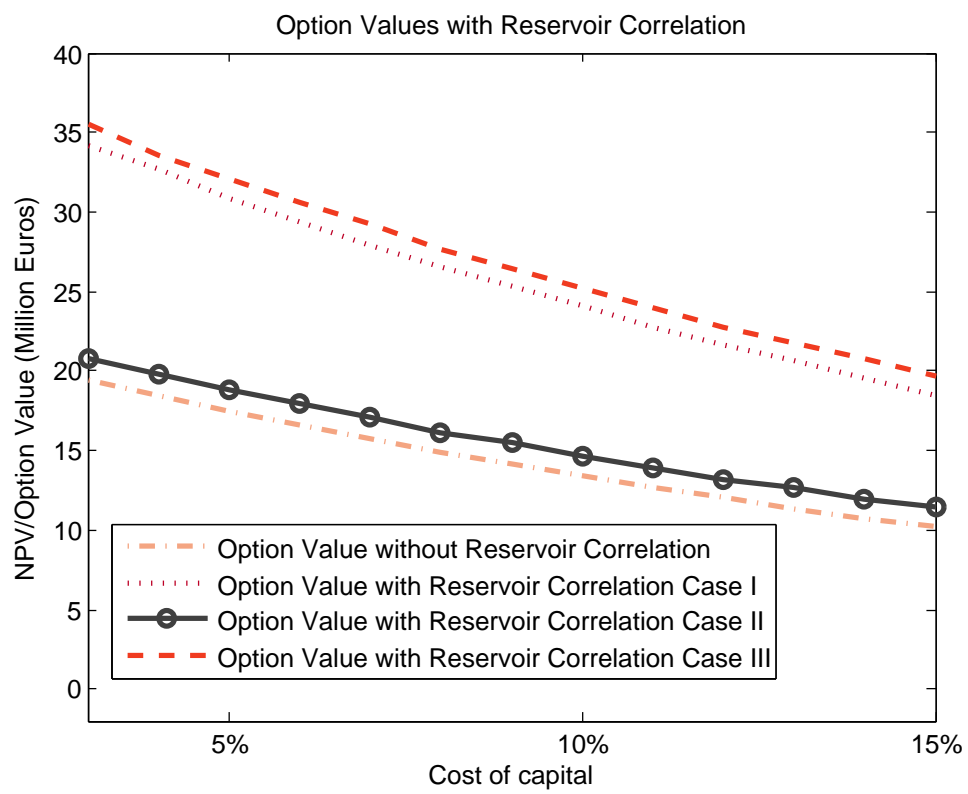

\subsection{Integrated Valuation Method}

\subsubsection{Results with and without reservoir information updates}

Next we explore the preference-dependent valuation given a particular utility structure of investors. The investor maximizes their utility function with idiosyncratic risk aversion (risk tolerance) $\gamma$. Instead of exploring a reasonable set of cost of capital, we use effective certainty equivalent to calculate option values based on different $\gamma$ within the context of incomplete market.

Figure 10 shows how option values change along with increasing risk tolerance, with or without reservoir correlation between $\mathrm{A}$ and $\mathrm{B}$. From left to right, as $\gamma$ becomes larger, the investor becomes more risk tolerant (i.e. less risk averse). It is clear that more risk averse investors value options less than investors with higher risk tolerance. Moreover, option value 
is a concave function of risk tolerance, meaning that the instantaneous acceleration of the option value is decreasing along with the risk tolerance. Although option values increase as the investor becomes more risk seeking (while still risk averse), preference dependence is moderate, resulting from the observation that the difference of option values between risk neutral and extremely risk averse investors is less than $6 \mathrm{mln}$ for a given reservoir correlation.

Figure 10: Results of Integrated Valuation Approach

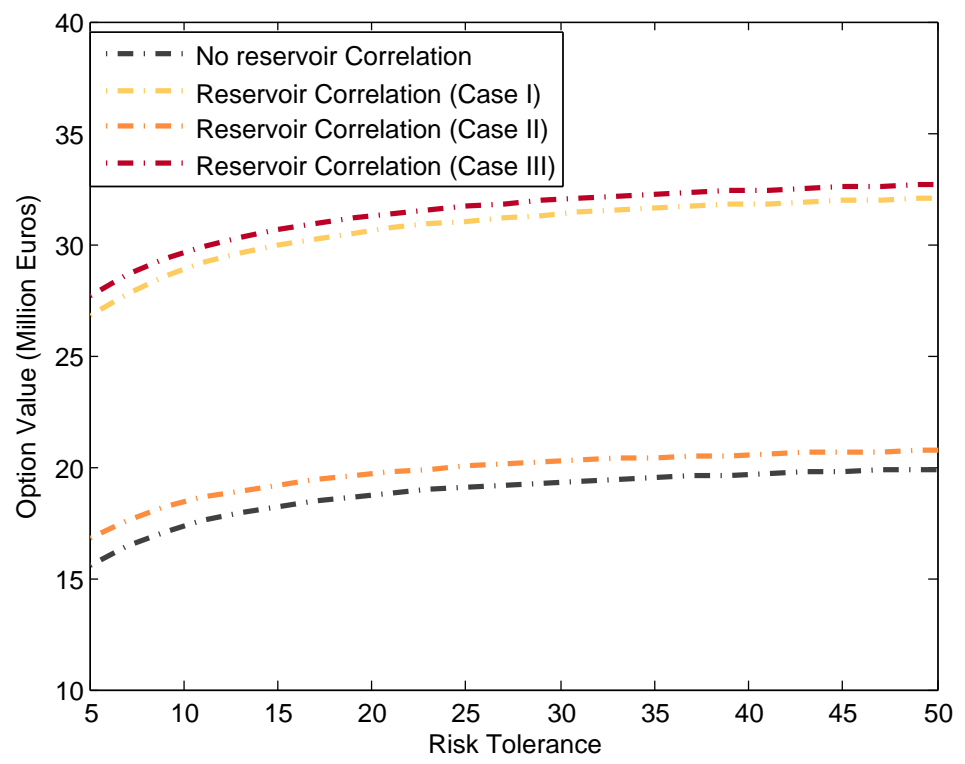

\subsubsection{GARCH vs Constant volatility}

Similar to 5.1.2, we compare the results with gas prices specified under a GARCH process and under a constant volatility assumption. Figure 11 shows that with a constant volatility setting, not only the option values largely shrink, but also the effect of future information update becomes smaller. This provides a strong empirical evidence that option value is largely undervalued if constant volatility, rather than a more appropriate GARCH model, is chosen for modeling underlying asset process. 
Figure 11: Results of Integrated Valuation Approach with Constant Volatility

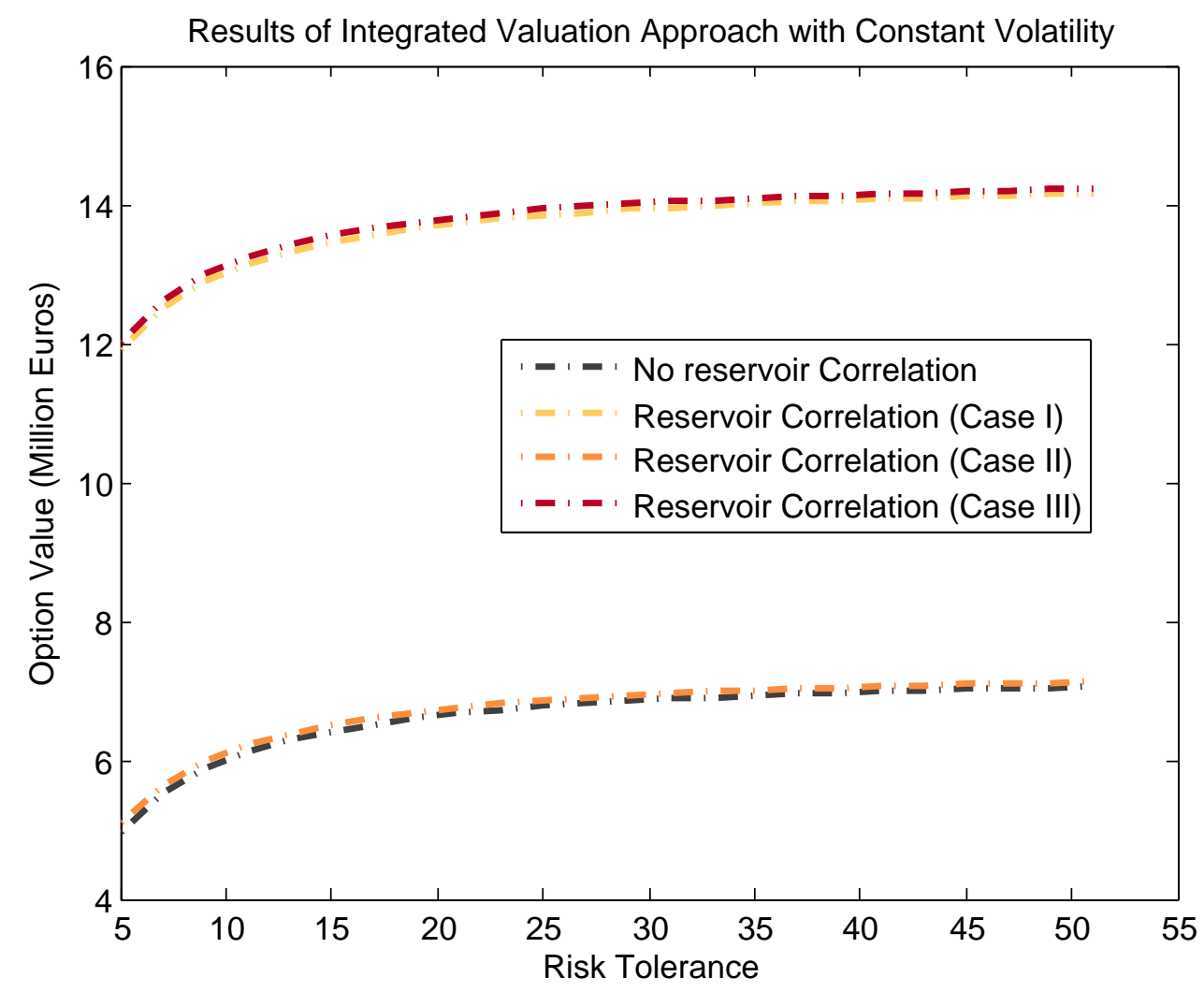




\subsection{Cost-of-Capital vs Integrated Valuation approach}

We apply two different methods for one single aim of capturing individuals preference in incomplete market asset pricing. The choice of cost-of-capital reflects an individual's risk preference; while the integrated valuation approach models investor's risk aversion explicitly with the parameter of risk tolerance.

Despite their different theoretical backgrounds, the results of these two approaches give largely similar results. First, project value increases substantially comparing to one obtained by traditional NPV method, which leads to potentially different investment decisions. Second, take the real option approach allows incorporation of future information as it becomes available, which again raises project values when reservoir distributions are correlated. Third, the GARCH specification is preferred over a model with constant volatility, since the latter undervalues the investment opportunity due to its oversimplification. In short, the value of embedded options is strongly influenced by the reservoir distribution and the stochastic process of gas prices.

Both approaches have their own pros and cons, which is why we present both. The costof-capital method is straightforward and closest to the traditional investor's capital budgeting processes in practice. However, it is not clear how to choose an appropriate value of cost-ofcapital for use. The integrated valuation approach provides the best results if one knows the

investor's risk preference. Survey methods could be used to pin down the investor's $\gamma$ (Cohen, Jaffray, and Said, 1987; Holt and Laury, 20027).

\section{Conclusion}

We have presented evidence regarding the effectiveness of investment valuation between real option analysis and NPV. In this paper, we have found that under Cost-of-capital method method, the option value is crucial in decision making process. We have also found that 
in the presence of clustered volatility, incorrectly assuming constant variance leads to an underestimation of project values.

An integrated approach is applied by taking investor's risk aversion into account. Results show that when the investor is not risk-neutral, option value increases as her risk aversion becomes smaller. Moreover, the correlation between reservoirs has also a positive effect on option values.

The results obtained from both methods are coherent in the sense that a choice of low cost of capital rate corresponds to a high risk tolerance.

Further analysis can be extended for research, among which one interesting direction lies in the dependence of productivity on market gas prices. A high market price might drive the firm to accelerate the producing rate. As the marginal cost of extraction is decreasing in the remaining amount of reservoir, the production plan may be changed with unexpected gas price realization. Thus the ex post production profile and costs become endogenous variables depending on gas prices.

Note that the algorithm and valuation approach in this paper can also be applied to general option pricing other than real options. For instance, it is very common that traders in reality hedge with proxy assets when a liquid market for the asset of interest does not exist. However the proxy asset is hardly perfectly correlated with the underlying asset, therefore the residual risk should be taken into consideration by specifying the investor's risk preference. 


\section{References}

[1] D.S. Bates. Empirical option pricing: A retrospection. Journal of Econometrics, 2003. $116,387-404$.

[2] F. Black and M. Scholes. The pricing of options and corporate liabilities. Journal of Political Economy, 1973. 81 (3): 637-654.

[3] T. Bollerslev. Generalized autoregressive conditional heteroskedasticity. Journal of Econometrics, 1986. 31, 307-327.

[4] A. Borison. Real option analysis: Where are the emperor's clothes. Journal of Applied Corporate Finance, Spring 2005. Volume 17, Number 2.

[5] S. Borenstein; C. Cameron and R. Gilbert. Do gasoline prices respond asymmetrically to crude oil price changes? The Quarterly Journal of Economics, Feb. 1997. Vol. 103, No. 3, 479-508.

[6] P. Carr and G. Yang. Simulating american bond options in an hjm framework. Quantitative Analysis in Financial Markets, Feb. 1998. Vol II, M.Avellaneda, ed.

[7] Jaffray Cohen and Said. Experimental comparison of individual behavoir under risk and under uncertainty for gains and for losses. Organaizational Behavoir and Human Decision Processes, 1987. 39, 1-22.

[8] T. Copeland and P. Tufano. A real-world way to manage real options. Harvard Business Review, Mar. 2004.

[9] F.C.J.M. de Jong. Valuation of pension fund liabilities in incomplete markets. Journal of Pension Economics and Finance, May 2008. 7(3), 277-294. 
[10] R.F. Dimitrakopoulos and S.A. Sabour. Evaluating mine plans under uncertainty: Can the real options make a difference? Resources Policy, Jun. 2007.

[11] A.K. Dixit and R.S. Pindyck. Investment under uncertainty. Princeton University Press, Princeton, NJ, 1994. ISBN 0-691-03410-9.

[12] J.C. Duan. The garch option pricing model. Mathematical Finance, 1995. 5(1), 13-32.

[13] R.F. Engle. Autoregressive conditional heteroscedasticity with estimates of the variance of united kingdom inflation. Econometrica, 1982. vol. 50, issue 4, pages 987-1007.

[14] O. Floroiu and A. Pelsser. Closed-form solutions for options in incomplete markets. Working paper, Feb. 2013.

[15] P. Hansen and A. Lunde. A forecast comparison of volatility models: does anything beat a garch(1,1)? Journal of Applied Econometrics, 2005. 20(7), 873-889.

[16] Holt and Laury. Risk aversion and incentive effects. The American Economic Review, 2002. 92,5 .

[17] F. Hubalek and W. Schachermayer. The limitations of no-arbitrage arguments for real options. International Journal of Theoretical and Applied Finance, 2001. 4,2, 361-373.

[18] F.A. Longstaff and E.S. Schwartz. Valuing american options by simulation: A simpleleastsquares approach. The Review of Financial Studies, 2001. Vol. 14, No.1.

[19] R. McDonald and D. Siegel. The value of waiting to invest. The Quarterly Journal of Economics, Nov. 1986. Volume 101, Issue 4, 707-728.

[20] D.B. Nelson. Conditional heteroskedasticity in asset returns: A new approach. Econometrica, 1991. 59, 347-370. 
[21] R.S. Pindyck. Volatility in natural gas and oil markets. Working Papers 0312, 2003. Massachusetts Institute of Technology, Center for Energy and Environmental Policy Research.

[22] R.S. Pindyck. Volatility and commodity price dynamics. The Journal of Futures Markets, 2004. Vol. 24, No. 11, 1029-1047.

[23] S. Poon and C.W.J. Granger. Forecasting volatility in financial markets: A review. Journal of Economic Literature, Jun. 2003. Vol. XLI pp. 478-539.

[24] L. Quigg. Empirical testing of real option-pricing models. The Journal of Finance, Jun. 1993. Vol. XLVIII, No. 2.

[25] J.C. Cox; S.A. Ross and M. Rubinstein. Option pricing: A simplified approach. Journal of Financial Economics, 1979. 7: 229-263.

[26] P. Sadorsky. Modeling and forecasting petroleum futures volatility. Energy Economics, 2006. 28 (4), 467-488.

[27] J.L. Paddock; D.R. Siegel and J.L. Smith. Option valuation of claims on real assets: The case of offshore petroleum leases. The Quarterly Journal of Economics, Aug. 1988. Vol. 103, No. 3, 479-508.

[28] J.E. Smith. Fisher separation and project valuation in partially complete markets. Fuqua School of Business, 1996. Working Paper.

[29] J.E. Smith and K.F. McCardle. Valuing oil properties: Intergrating option pricing and decision analysis approaches. Operations Research, March-April 1998. Vol. 46, No. 2.

[30] J.E. Smith and K.F. McCardle. Options in the real world: Lessons learned in evaluating oil and gas investments. Operations Research, Jan.-Feb. 1999. 47(1): 1-15. 
[31] J.E. Smith and R.F. Nau. Valuing risky projects: Option pricing theory and decision analysis. Management Science, 1995. 41, 795-816.

[32] L. Stentoft. Pricing american options when the underlying asset follows garch processes. Journal of Empirical Finance, 2005. 12 (4), 576-611.

[33] L. Trigeorgis. Real options: Management flexibility and strategy in resource allocation. MIT Press, Cambridge, Mass., 1996. 


\section{A LSMC for Cost-of-Capital method}

Inputs include risk-free return $r_{f}$, cost of capital $r$, production profile: $\left\{G_{1}^{B}, G_{2}^{B}, \ldots, G_{T_{B}}^{B}\right\}$ and $\left\{G_{1}^{A}, G_{2}^{A}, \ldots, G_{T_{A}}^{A}\right\}$ and corresponding costs $\left\{C_{1}^{B}, C_{2}^{B}, \ldots, C_{T_{B}}^{B}\right\}$ and $\left\{C_{1}^{A}, C_{2}^{A}, \ldots, C_{T_{A}}^{A}\right\}$.

1. Generate $N$ paths, with gas prices simulated from $\mathrm{MA}(2)-\operatorname{GARCH}(1,1)$ and reservoir size simulated from the distribution illustrated in Section 3.2.

\section{Compound Option on B}

(a) Exercise Strategy Matrix: $E$ is $N \times(M+1)$ matrix, with 1 as exercise and 0 as no exercise, where $M+1$ is the number of predetermined exercise dates.

(b) $N P V_{t_{B}}^{B}=P O S^{B} \times \sum_{t_{i}=t_{B}}^{t_{B}+T_{B}} \exp \left(-r\left(t_{i}-t_{B}\right)\right)\left(P_{t_{i}}^{B} G_{t_{i}}^{B}-C_{t_{i}}^{B}\right)$, with $G_{t}=0$, where $t_{B} \in I$ as shown in Figure 3.

(c) The analysis starts at the final moment when the firm can make a decision, i.e. $t_{M}=T-1-T_{A}-T_{B}$.

i. At $t=t_{M}$, if exercise at path $j$, the exercise value includes not only the payoff from B, i.e. $X_{t_{M}, j}=N P V_{t_{M}, j}^{B}$, but also an option on A. The option value of A at time $t_{M}$ for path $j$ is

$$
A_{t_{M}, j}=\max _{t \in I I} \mathbb{E}_{t_{M}}\left(\exp \left(-r_{f}\left(t-t_{M}\right)\right) \max \left(N P V_{t, j}^{A \mid B}, 0\right)\right)
$$

where $I I$ is shown in Figure 3 and

$$
N P V_{t, j}^{A \mid B}=P O S^{A \mid B} \sum_{t_{i}=t_{A}}^{t_{A}+T_{A}} \exp \left(-r\left(t_{i}-t_{A}\right)\right)\left(P_{t_{i}}^{A} G_{t_{i}}^{A}-C_{t_{i}}^{A}\right)
$$

Suppose $\tau$ is the set of stopping time $\left\{t: t_{0}^{A}, t_{1}^{A}, \ldots, t_{L}^{A}\right\}^{8}$, while $\tau \backslash\left\{t<t_{M}\right\}$ represents the possible exercising date set of starting drilling A, i.e. $I I=$

\footnotetext{
${ }^{8} L+1$ is the number of predetermined exercise dates for $\mathrm{A}$.
} 
$\left\{t: t_{0}^{A}, t_{1}^{A}, \ldots, t_{L}^{A}\right\} \cap\left\{t \geq t_{M}\right\}$, with regard to $\sigma$-algebra $\left\{\mathcal{F}_{t}\right\}$. Therefore, the compound option value on B becomes

$$
\max _{t \in \tau_{B}} \mathbb{E}_{0}\left(\exp \left(-r_{f} t\right) \max \left(X_{t, j}+A_{t, j}, 0\right)\right)
$$

ii. Define $X_{t_{M}, j}^{\prime}=X_{t_{M}, j}+A_{t_{M}, j}$ and $Y_{t_{M-1}, j}^{\prime}=\exp \left(-r_{f}\left(t_{M}-t_{M-1}\right)\right) X_{t_{M}, j}^{\prime}$, for all $j \in\left\{j: X_{t_{M}, j}^{\prime}>0\right\}$.

iii. At $t=t_{M}$, if $X_{t_{M}, j}^{\prime}>0$, exercise the option and let $E(j, M+1)=1$; if $X_{t_{M}, j}^{\prime} \leq 0$, abandon the project and let $E(j, M+1)=0$.

iv. Move one step backward. At $t=t_{M-1}$, regress $Y_{t_{M-1}, j}^{\prime}$ on a set of basis functions of $X_{t_{M-1}, j}^{\prime}$, for instance, a set of a constant, $X_{t_{M-1}, j}^{\prime}$, and $X_{t_{M-1}, j}^{\prime 2}$.

$$
Y_{t_{M-1}, j}^{\prime}=\beta_{0}+\beta_{1} X_{t_{M-1}, j}^{\prime}+\beta_{2} X_{t_{M-1}, j}^{\prime 2}+u_{j}^{\prime}
$$

Longstaff and Schwartz (2001) shows that the results from the Least Square Monte Carlo algorithm are significantly robust to the choice of basis functions. Adding extra high degree of basis functions does not help improving accuracy noticeably.

v. It is take-it-or-leave-it choice that the firm will exercise the option to produce if $X_{t_{M}, j}^{\prime}>0$ and not otherwise. Compare the continuation value $\hat{Y}^{\prime} t_{M-1}, j$ with immediate payoff $X_{t_{M}, j}^{\prime}$. If $\hat{Y}_{t_{M-1}, j}^{\prime}>X_{t_{M}, j}^{\prime}$, which means continuation value is higher than exercise at $t_{M-1}$, the corresponding exercise strategy is not to exercise, i.e. $E(j, M)=0$; while if $\hat{Y}_{t_{M-1}, j}^{\prime}<X_{t_{M}, j}^{\prime}$, the firm finds it more profitable to exercise right now rather than to wait for next exercise date, resulting in $E(j, M)=1$, and $E(j, M+1)$ is updated to 0 whatever it was given last step at time $t_{M}$. Table 2-a and Table 2-b explain the idea of LSMC. 
It compares the net present value at each exercise moment with the optimal net present value of next exercise date discounted into the current exercise date.

vi. By proceeding recursively, we again obtain an exercise strategy matrix $E$ with only zero or one as its elements. Similarly, there is at most one exercise date denoted by one for each simulation path, i.e. each row of $E$, which is followed by zeros till the expiration date of the option.

(d) The option value is calculated by averaging discounted current cash flow of $X_{t, j}^{\prime}$ on the exercising date across paths.

\section{B GARCH}

\section{B.1 Unit Root Test}

Table 3 exhibits the results of Phillips-Perron Unit Root Test and Dickey-Fuller Unit Root Test.

The Phillips-Perron unit root test on $P_{t}$ indicates rejecting the stationarity hypothesis of $P_{t}$ under $95 \%$ confidence with a p-value 0.0639. While the corresponding Dickey-Fuller test yields different result and suggests no presence of unit root in the times series $P_{t}$. The problem with Dickey-Fuller test is that if time series varies much across time, it is more likely to accept the stationarity hypothesis. And unit root test on $\ln P_{t}$ also rejects the hypothesis that the price time series is stationary under $95 \%$ confidence level. So in this case, I am more inclined to accepting the results suggested by Phillips-Perron test that $P_{t}$ has a deterministic trend.

Furthermore, observed from the unit root test, first difference of gas prices, or first difference of $\log$ prices are stationary time series with p-value 0.0000 . Only stochastic trend exists in this time series. By observing Figure $4 \mathrm{~b}$, the log price returns series moves with gradual upward and downward fluctuations around a long-term mean. Since the first difference series 

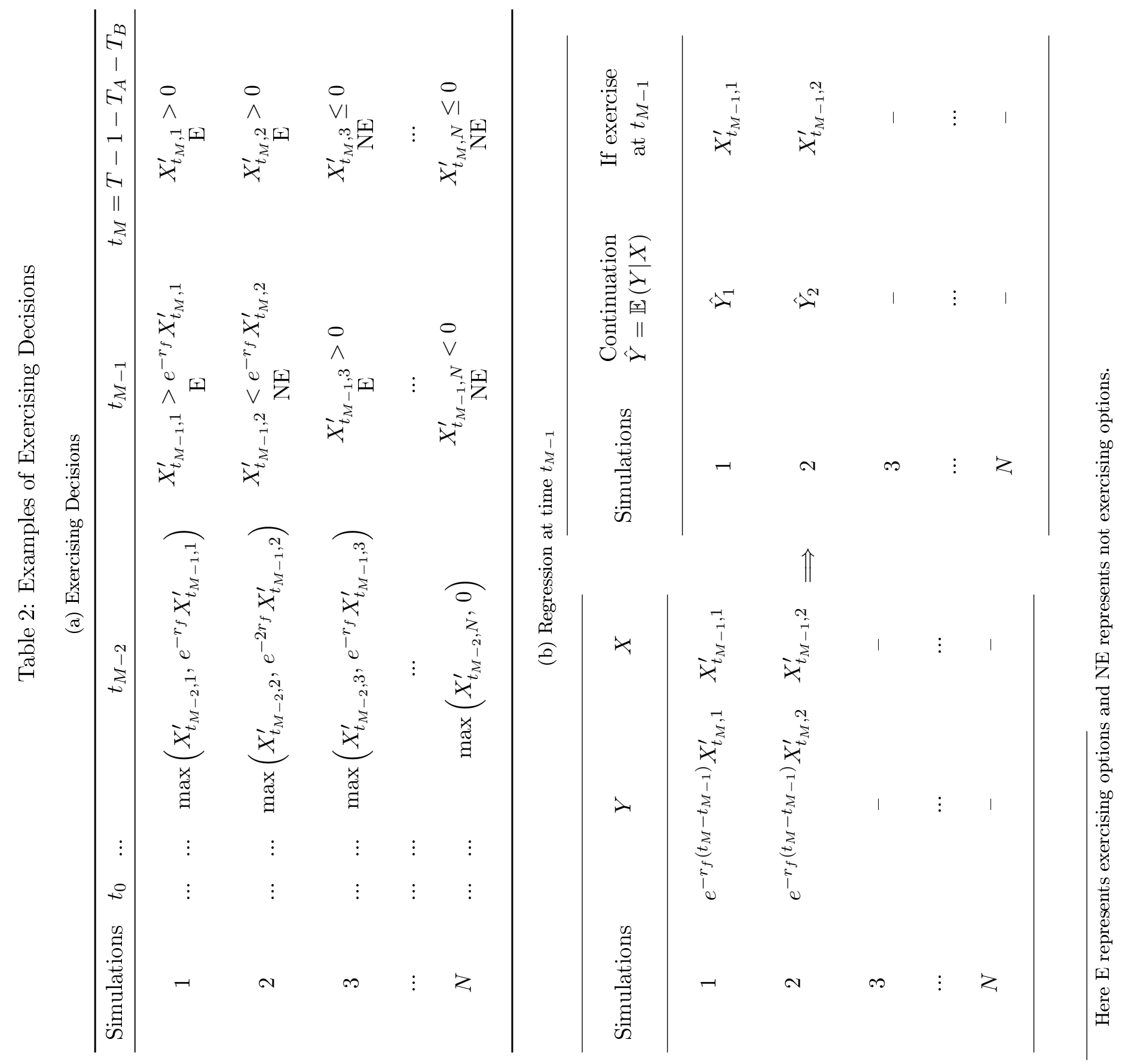
Table 3: Unit Root Tests Results (p-values)

\begin{tabular}{c|cc}
\hline & Phillips-Perron Unit Root Test & Dickey-Fuller Unit Root Test \\
\hline \hline$P_{t}$ & 0.0639 & 0.0182 \\
$\ln P_{t}$ & 0.1321 & 0.0740 \\
$\Delta P_{t}$ & 0.0000 & 0.0000 \\
$\Delta \ln P_{t}$ & 0.0000 & 0.0000 \\
\hline
\end{tabular}

is stationary and contains no trend, I proceed to investigate the logarithm return time series.

\section{B.2 Model Estimation and Diagnostic Tests}

The sample autocorrelations and partial autocorrelations are plotted as in Figure 12 to give a first indication on how to choose the lag structure of a possibly adequate ARMA model.

The second order of ACF and PACF of log weekly returns are significant. Both ACF and PACF are small but slowly decaying, which implies an ARMA model might be suitable for $\Delta \ln P_{t}$. Note that the 20th order of ACF and PACF is also significant, but this has no intuitive meaning and might be due to random effect. Now we determine the choice of lag terms by comparing several estimated models, i.e. autoregressive models, moving average models, or mixed ARMA models as shown in Table 4.

Table 4 illustrates the results of AR, MA and ARMA models with lag terms up to 3. Ljung-Box $Q$ tests examine the existence of autocorrelation in the standardized residuals, while Ljung-Box $Q^{2}$ tests examine the existence of autocorrelation in the squared standardized residuals. Of these ten models, MA(2) model is preferred according to the AIC and SIC selection criteria. However, the squared residuals of the MA(2) model have some significant autocorrelations (for instance at lag 40, corresponding to a lag of three quarters). Thus it is worthwhile comparing this model with other models that allow for a richer correlation pattern in the time series. Elimination of this correlation cannot be achieved only by adding extra 
Figure 12: $\mathrm{AC}$ and $\mathrm{PAC}$ of $\Delta \ln P_{t}$

(a) Autocorrelation Plot of $\Delta \ln P_{t}$

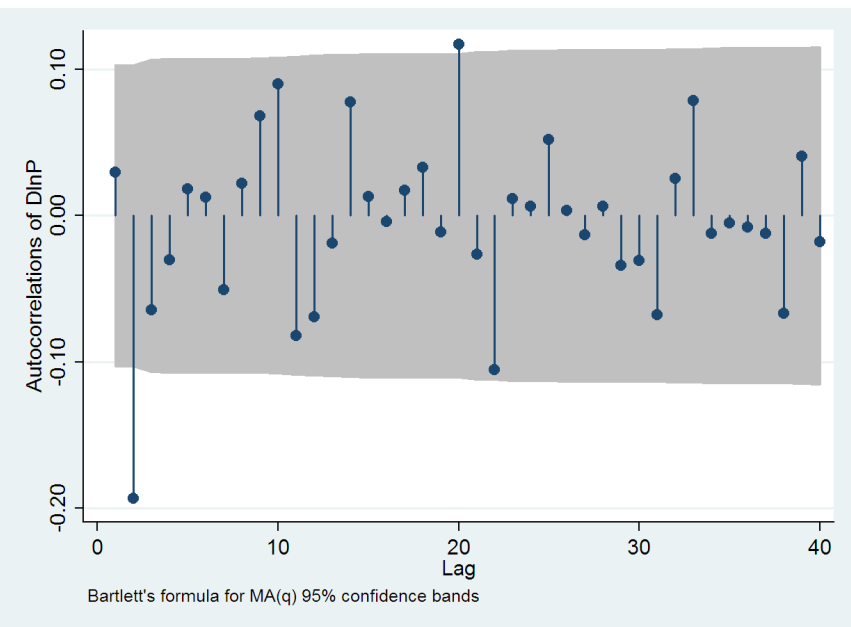

(b) Partial Autocorrelation Plot of $\Delta \ln P_{t}$

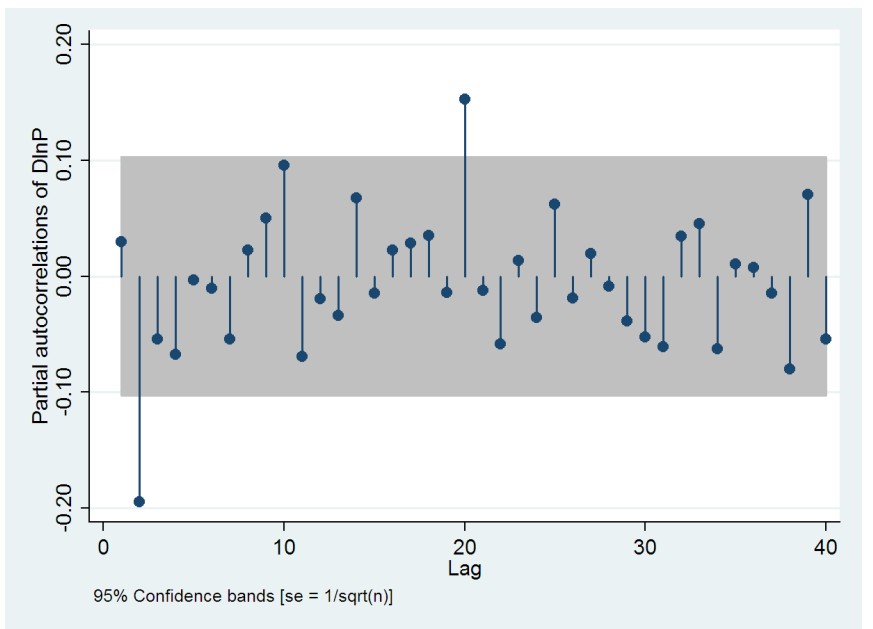




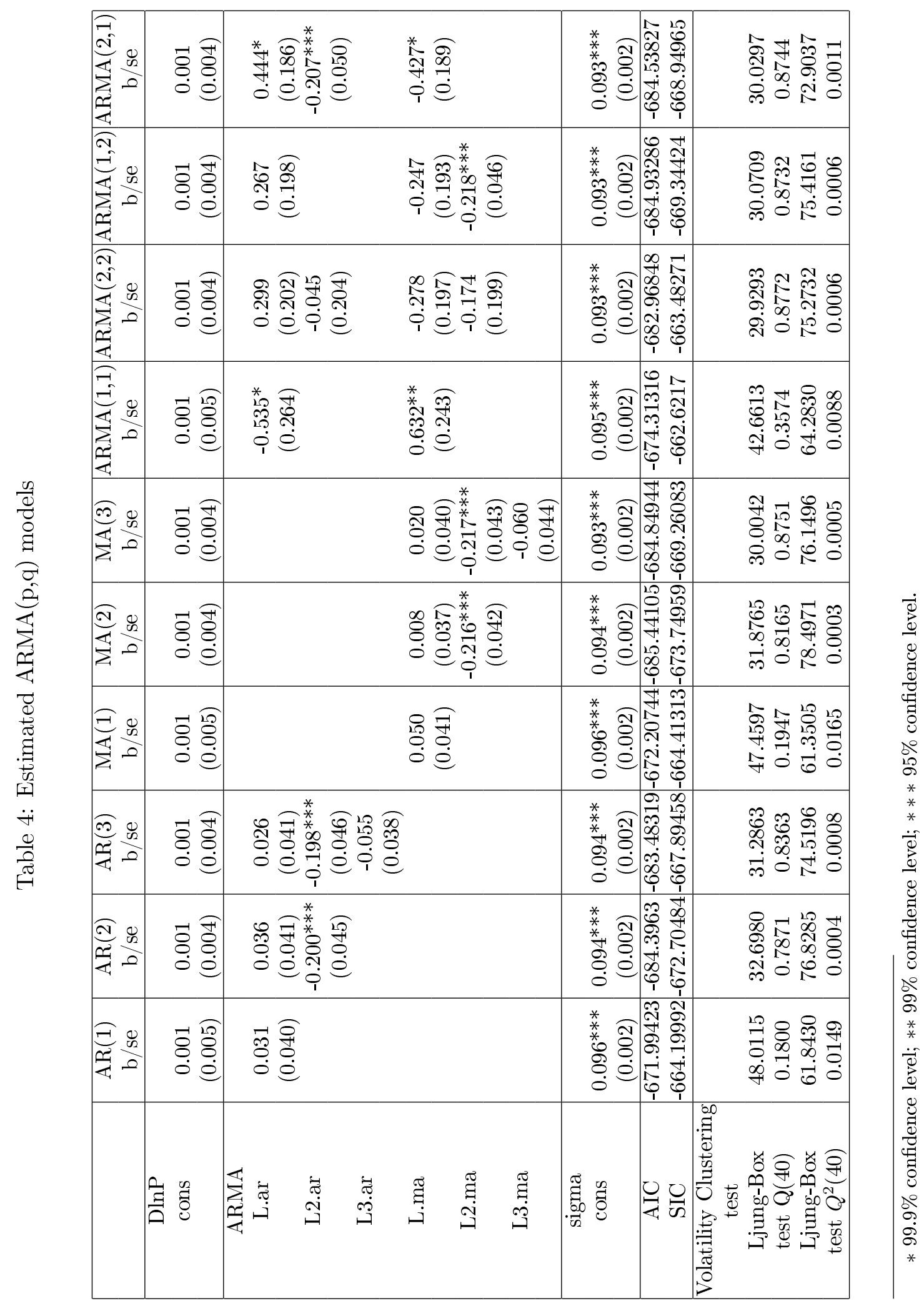


lags to the model, since the correlations still exist in MA(3). Evaluated by diagnostic tests, current ARMA models are not able to capture the main correlations in the time series $\Delta \ln P_{t}$ under a confidential level 95\%, since the volatility clustering tests reject the non-existence of GARCH effects. Although MA(2) minimizes the information criteria AIC and BIC, I cannot simply apply it since the diagnostic checking of volatility clustering reveals that the variances of residuals are correlated. Models with higher lag structures correspond to over-fitting, which also result in even worse predictions than $\mathrm{MA}(2)$. In order to produce reliable forecasts, an ARCH or GARCH factor is introduced to AR, MA or mixed ARMA model.

The evidence from Table 5 and Table 6 shows that the variance in the log returns is correlated and changes over time. The rejection of non-correlation of squared residuals indicates the assumption that the innovations $\varepsilon_{t}$ have the same variance $\sigma_{t}^{2}$ is not realistic and the conditional variance of the time series may have lagged effects. According to Ljung-Box test results, an MA(2)-GARCH(1,1) model is preferred over an $\mathrm{MA}(2)-\mathrm{ARCH}(1)$ model, since the latter still yields variance clustering of innovations. This is also consistent with Poon and Granger (2002) that empirical findings suggest GARCH model is a more parsimonious model than ARCH model. Stentoft (2005) argues that allowing different mean specifications generally does not change the dynamics under the equivalent martingale measure.

Let $P_{t}$ be spot gas price at time $t$. Suppose under risk-neutral probability measure $\mathbb{Q}$, its one-period rate of return has conditionally lognormal distribution, i.e.

$$
\begin{aligned}
\ln \frac{P_{t}}{P_{t-1}}= & \mu-\frac{1}{2} h_{t}+\varepsilon_{t}+\beta_{1} \varepsilon_{t-1}+\beta_{2} \varepsilon_{t-2}, \\
h_{t}= & \alpha_{0}+\alpha_{1}\left(\varepsilon_{t-1}-\lambda \sqrt{h_{t}}\right)^{2}+\alpha_{2} h_{t-1}, \\
\text { where } \quad & \varepsilon_{t} \mid \mathscr{F}_{t-1} \sim N\left(0, h_{t}\right)
\end{aligned}
$$

Here, $\mathscr{F}_{t-1}$ is the information set up to and including time $t-1 ; \alpha_{0}>0, \alpha_{1}, \alpha_{2} \geq 0$ so 


\begin{tabular}{|c|c|c|c|c|c|c|}
\hline 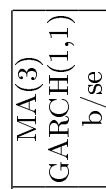 & $\begin{array}{ll}0 & \vec{b} \\
0 & \vdots \\
0 & 0 \\
1\end{array}$ & & 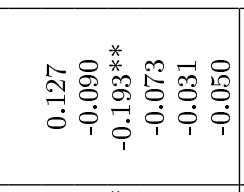 & 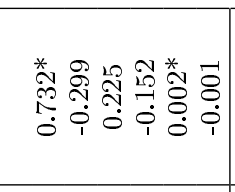 & $\left|\begin{array}{lll}\infty & 0 & +1 \\
0 & 0 & 0 \\
\infty & 0 & 0 \\
0 & 2 & 1 \\
0 & 0 & -1 \\
0 & 0 & 0 \\
\infty & 1 & 0 \\
0 & 1 & 1\end{array}\right|$ & 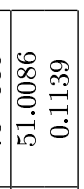 \\
\hline 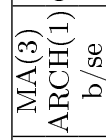 & 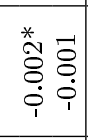 & & 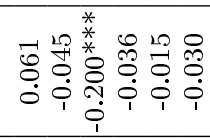 & 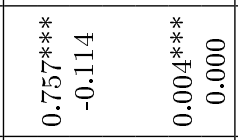 & 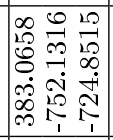 & 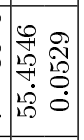 \\
\hline 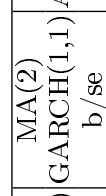 & $\begin{array}{lll}0 & \vec{b} \\
\vdots & 0 \\
0 & 0 \\
\vdots\end{array}$ & & 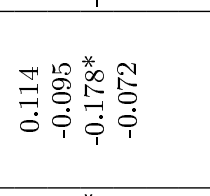 & 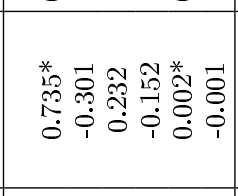 & 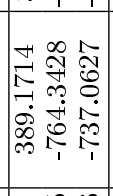 & 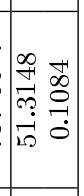 \\
\hline 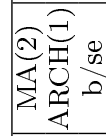 & 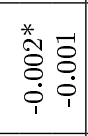 & & 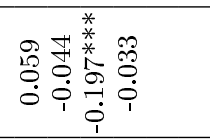 & 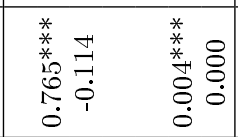 & 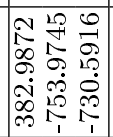 & 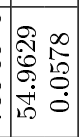 \\
\hline 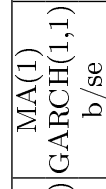 & $\begin{array}{lll}\vec{c} & \overrightarrow{0} \\
0 & 0 \\
i & 0 \\
\vdots & 0\end{array}$ & & 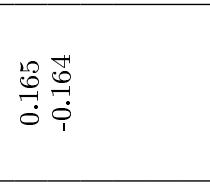 & 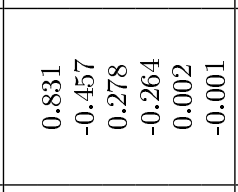 & 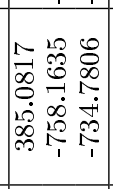 & 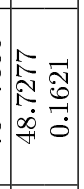 \\
\hline 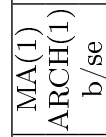 & $\begin{array}{ll}\vec{z} & \vec{z} \\
0 & 0 \\
i & 0 \\
1 & 0\end{array}$ & & $\begin{array}{ll}* & 0 \\
\text { * } & 0 \\
0 & 0 \\
0 & 0 \\
0 & 0 \\
0 & 0 \\
0 & 1\end{array}$ & 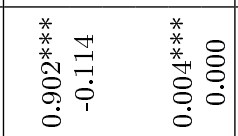 & 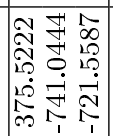 & 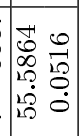 \\
\hline 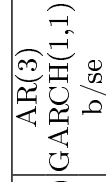 & 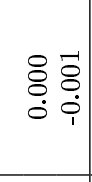 & 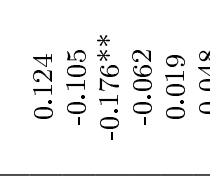 & & 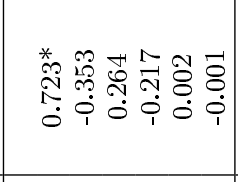 & 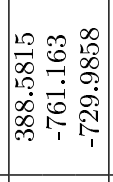 & 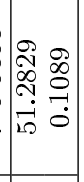 \\
\hline 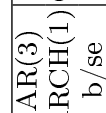 & \begin{tabular}{l}
$*$ \\
\multirow{0}{*}{} \\
0 \\
0 \\
0 \\
0
\end{tabular} & 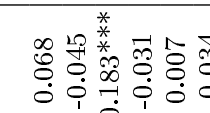 & & 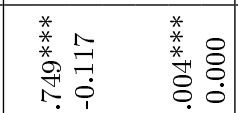 & 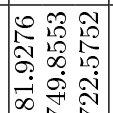 & $\mid$\begin{tabular}{ll|}
1 & \\
\hdashline & 0 \\
0 & 0 \\
\hdashline & 0 \\
2 & 0 \\
2 & 0 \\
0
\end{tabular} \\
\hline$\sqrt{2}$ & & $i^{1}$ & & $0^{1} \quad 0$ & 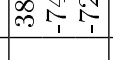 & 200 \\
\hline 永焉 & 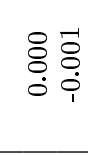 & 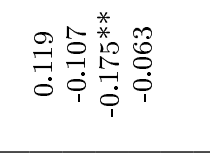 & & 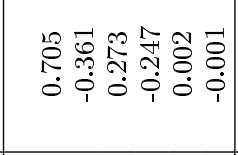 & 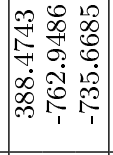 & $\left|\begin{array}{cc}0 & 0 \\
2 & \ddots \\
0 & \ddots \\
& 7 \\
10 & 0\end{array}\right|$ \\
\hline 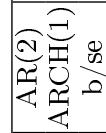 & 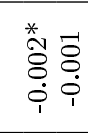 & 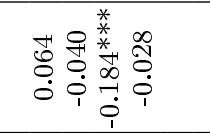 & & 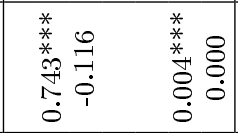 & 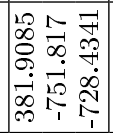 & $\begin{array}{|ll|}0 & 0 \\
10 \\
0 \\
0 & 0 \\
10 & 0 \\
10 & 0 \\
10 & 0 \\
\end{array}$ \\
\hline 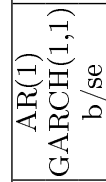 & 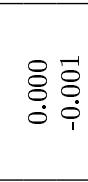 & $\begin{array}{ll}2 & 10 \\
0 & \stackrel{1}{0} \\
0 & 0 \\
0 & 1\end{array}$ & & 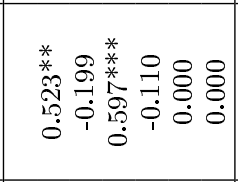 & 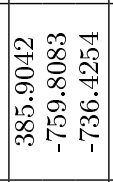 & 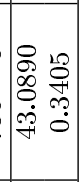 \\
\hline 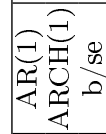 & $\begin{array}{ll}\overrightarrow{8} & \overrightarrow{8} \\
0 & 0 \\
i & 0 \\
1 & 1\end{array}$ & 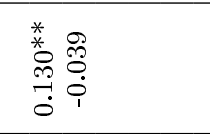 & & 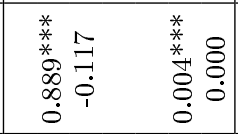 & 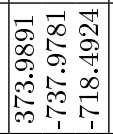 & 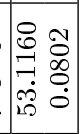 \\
\hline & 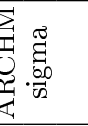 & 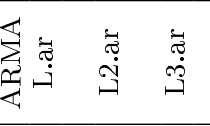 & 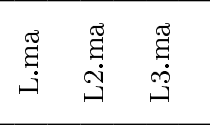 & 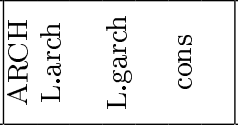 & 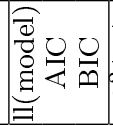 & 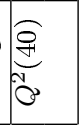 \\
\hline
\end{tabular}




\begin{tabular}{|c|c|c|c|c|c|c|c|c|c|}
\hline 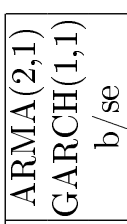 & \begin{tabular}{ll}
8 & $:$ \\
8 & 8 \\
\hdashline & 0
\end{tabular} & \multicolumn{3}{|c|}{ 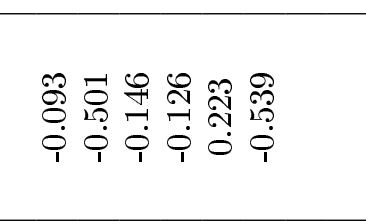 } & \multicolumn{3}{|c|}{ 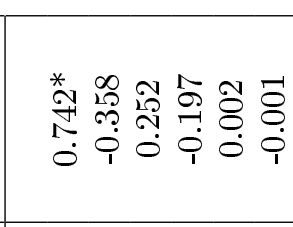 } & 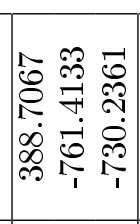 & 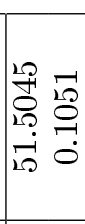 \\
\hline 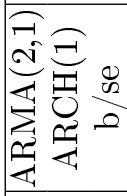 & 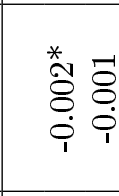 & \multicolumn{3}{|c|}{ 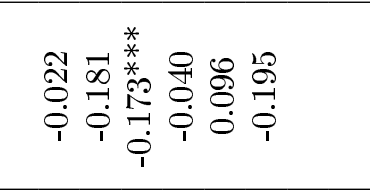 } & 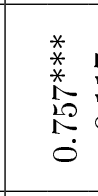 & & $\begin{array}{ll}\stackrel{*}{*} & 8 \\
\stackrel{*}{*} & 8 \\
8 & 0 \\
0 & 0 \\
0\end{array}$ & 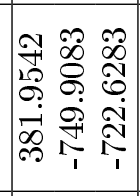 & 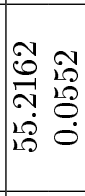 \\
\hline 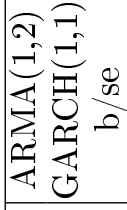 & \begin{tabular}{l}
8 \\
8 \\
8 \\
\hdashline \\
0
\end{tabular} & \multicolumn{3}{|r|}{ 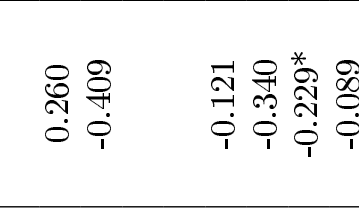 } & \multicolumn{3}{|c|}{ 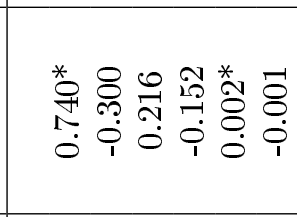 } & 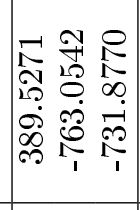 & \begin{tabular}{ll}
$-\infty$ & 1 \\
$\infty$ & 0 \\
0 & 0 \\
0 & $\ddots$ \\
0 & $\ddots$ \\
\hdashline & 0
\end{tabular} \\
\hline 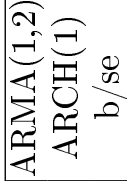 & $\begin{array}{ll}\stackrel{*}{*} & \overline{8} \\
\overbrace{0} & 0 \\
0 & 0 \\
& 1\end{array}$ & \multicolumn{3}{|r|}{ 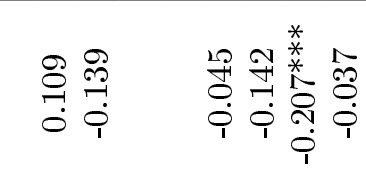 } & \multicolumn{3}{|c|}{ 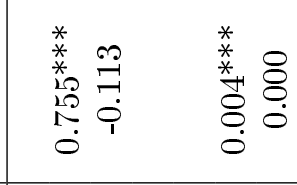 } & 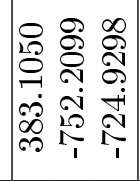 & 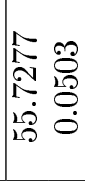 \\
\hline 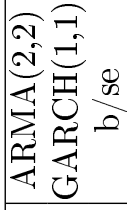 & $\begin{array}{l}8 \\
8 \\
8 \\
0 \\
0\end{array}$ & \multicolumn{3}{|c|}{ 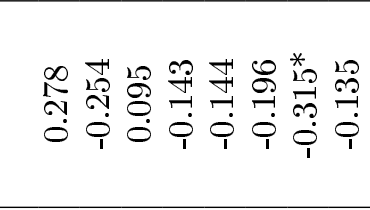 } & \multicolumn{3}{|c|}{ 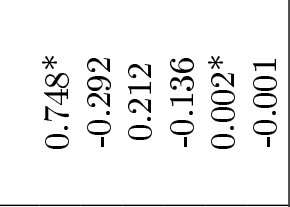 } & 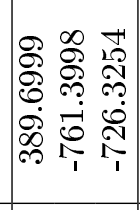 & 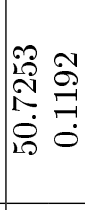 \\
\hline 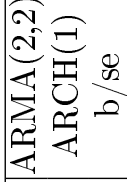 & $\begin{array}{ll}\stackrel{*}{*} & \overline{8} \\
\stackrel{8}{0} & 0 \\
0 & 0 \\
0 & 1\end{array}$ & \multicolumn{3}{|c|}{ 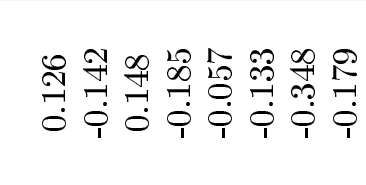 } & \multicolumn{3}{|c|}{ 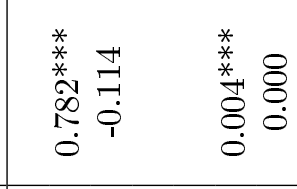 } & 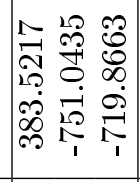 & 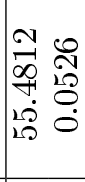 \\
\hline 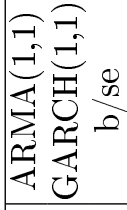 & $\begin{array}{ll}\overrightarrow{8} & \overrightarrow{8} \\
0 & 0 \\
\dot{\varphi} & 0\end{array}$ & 草 & & 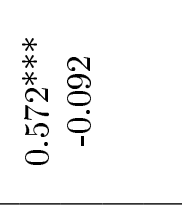 & \multicolumn{3}{|c|}{ 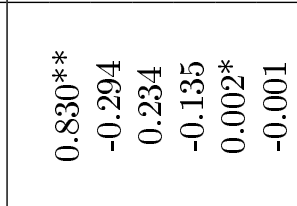 } & 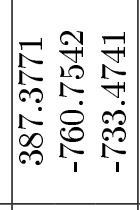 & 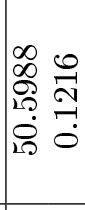 \\
\hline \multirow[t]{2}{*}{ 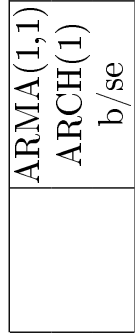 } & $\begin{array}{ll}\overrightarrow{8} & \overline{8} \\
0 & 0 \\
0 & 0 \\
1 & 1\end{array}$ & \multicolumn{3}{|c|}{ 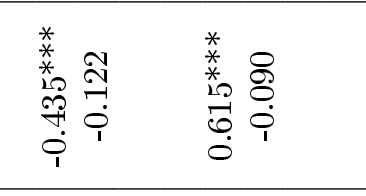 } & \multicolumn{3}{|c|}{$\begin{array}{ll}\stackrel{*}{*} & \stackrel{20}{*} \\
\stackrel{*}{2} & \stackrel{1}{1} \\
\stackrel{0}{0} & 1 \\
0 & 1\end{array}$} & 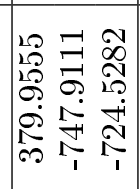 & \begin{tabular}{ll}
$\infty$ & 8 \\
$\infty$ & 8 \\
\multirow{1}{*}{} & 0 \\
$\infty$ & 0 \\
$\infty$ & 0 \\
20 & 0
\end{tabular} \\
\hline & 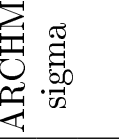 & 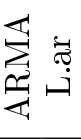 & 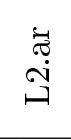 & 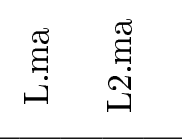 & 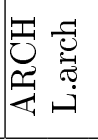 & 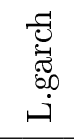 & $\begin{array}{l}\text { है } \\
\text { है }\end{array}$ & 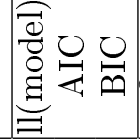 & 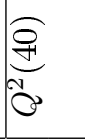 \\
\hline
\end{tabular}

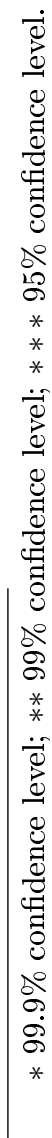


that non-negative variance is guaranteed. Similarly, to ensure its stationarity, $\alpha_{1}$ and $\alpha_{2}$ need to satisfy $\alpha_{1}+\alpha_{2}<1$.

Note that both $\operatorname{AR}(2)-\operatorname{GARCH}(1,1)$ model and $\mathrm{MA}(2)-\operatorname{GARCH}(1,1)$ have the smallest $\mathrm{AIC}$ or BIC values. However, the coefficients of $\mathrm{ARCH}$ and GARCH effects of the AR(2)GARCH $(1,1)$ model are not significant. The coefficients of ARCH and GARCH effects of the AR(1)-GARCH(1,1) model add up to bigger than one, violating the stationary condition of GARCH model. An IGARCH model might be employed to solve the non-stationary problem. Yet IGARCH is not covariance stationary and is not attractive from empirical point of view. So an $\mathrm{MA}(2)$ - $\mathrm{GARCH}(1,1)$ model is chosen over $\operatorname{AR}(2)-\operatorname{GARCH}(1,1)$ and $\operatorname{AR}(1)-\operatorname{GARCH}(1,1)$.

\section{B.3 Seasonal Effects}

The time series of gas price has a significant seasonal component due to changes in demand. This seasonal effect can be detected from Figure 4 by observing that the prices are much higher in winter (Q1 and Q4) than in summer (Q2 and Q3). However, the existence of a seasonal effect is not observable when it comes to logarithm returns instead of price levels. Table 7 shows the results of adding seasonal components to the $\mathrm{MA}(2)-\operatorname{GARCH}(1,1)$ model. All the four season dummies are insignificant and adding season dummies does not yield a smaller information criteria AIC or BIC. These results lead to rejecting the existence of deterministic seasonal effects and confirming our choice of an $\mathrm{MA}(2)-\mathrm{GARCH}(1,1)$ model.

\section{B.4 EGARCH}

In addition, I continue to examine the existence of asymmetric shocks, i.e. whether the gas trading market as a whole responds differently to unanticipated increases in spot prices than it does to unanticipated decreases. One of these models is Exponential GARCH (EGARCH) model, first proposed by Nelson (1991). Stentoft (2005) finds the specifications of EGARCH generally have the smallest pricing errors concerning options on individual stocks. 
Table 7: Seasonality Effect Tests

\begin{tabular}{|c|c|c|}
\hline & $\begin{array}{c}\mathrm{MA}(2)-\mathrm{GARCH}(1,1) \\
\text { Seasonality } \\
\text { b/se }\end{array}$ & $\begin{array}{c}\mathrm{MA}(2)-\mathrm{GARCH}(1,1) \\
\mathrm{b} / \mathrm{se}\end{array}$ \\
\hline \multicolumn{3}{|l|}{$\mathrm{D} \ln \mathrm{P}$} \\
\hline & -0.017 & \\
\hline & -0.013 & \\
\hline \multirow[t]{2}{*}{$\mathrm{s} 2$} & -0.007 & \\
\hline & -0.012 & \\
\hline \multirow[t]{3}{*}{ s3 } & 0.006 & \\
\hline & -0.013 & \\
\hline & -0.020 & -0.015 \\
\hline \multirow{3}{*}{$\begin{array}{l}\text { ARCHM } \\
\text { sigma2ex }\end{array}$} & & \\
\hline & 0.000 & 0.000 \\
\hline & -0.001 & -0.001 \\
\hline \multirow{3}{*}{$\begin{array}{c}\text { ARMA } \\
\text { L.ma }\end{array}$} & & \\
\hline & 0.118 & 0.114 \\
\hline & -0.091 & -0.095 \\
\hline \multirow[t]{2}{*}{ L2.ma } & $-0.175^{*}$ & $-0.178^{*}$ \\
\hline & -0.079 & -0.072 \\
\hline \multirow{3}{*}{$\begin{array}{l}\text { ARCH } \\
\text { L.arch }\end{array}$} & & \\
\hline & $0.785^{*}$ & $0.735^{*}$ \\
\hline & -0.308 & -0.301 \\
\hline \multirow[t]{2}{*}{ L.garch } & 0.232 & 0.232 \\
\hline & -0.126 & -0.152 \\
\hline \multirow[t]{2}{*}{ cons } & $0.002^{*}$ & $0.002^{*}$ \\
\hline & -0.001 & -0.001 \\
\hline $11($ model $)$ & 389.1714 & 390.3984 \\
\hline $\mathrm{AIC}$ & -764.3428 & -760.7968 \\
\hline $\mathrm{BIC}$ & -737.0627 & -721.8528 \\
\hline
\end{tabular}

$* 99.9 \%$ confidence level; $* * 99 \%$ confidence level; $* * * 95 \%$ confidence level. 
We modify the conditional variance of the GARCH model proposed above as follows:

$$
\log \left(h_{t}\right)=\alpha_{0}+\alpha_{1} z_{t-1}+\alpha_{2} \log \left(h_{t-1}\right)+\alpha_{3}\left(\left|z_{t-1}\right|-E\left[\left|z_{t-1}\right|\right]\right)
$$

where $z_{t}=\varepsilon_{t} / h_{t}$ is the standardized residual, which is distributed as $N(0,1) . \quad \alpha_{3}$ is the asymmetric component and $\left|\alpha_{2}\right|<1$ ensures stationarity and ergodicity for the $\operatorname{EGARCH}(1,1)$ model.

Table 8 shows the results of $\operatorname{ARMA}(\mathrm{p}, \mathrm{q})-\operatorname{EGARCH}(1,1)$ models, where only $\operatorname{ARMA}(\mathrm{p}, \mathrm{q})$ models without over fitting are considered. Judging from the information criteria, MA(2)EGARCH(1,1) outperforms the other models, with the smallest AIC and BIC, which confirms the model selection above. $\mathrm{MA}(2)-\operatorname{EGARCH}(1,1)$ fits the data better in terms of the model loglikelihood. We observe that EGARCH models yield larger loglikelihood than the GARCH model, implying a slightly better fit. Furthermore, MA(2)-EGARCH(1,1) results in the variance

$$
\begin{gathered}
\log h_{t}=-0.588+0.009 z_{t-1}+0.873 \log h_{t-1}+0.672\left(\left|z_{t-1}\right|-E\left[\left|z_{t-1}\right|\right]\right) \\
\text { (.) } \quad(-0.068) \quad(-0.005)
\end{gathered}
$$

A positive L1.earch coefficient implies that positive innovations (unanticipated price increases) are more destabilizing than negative innovations and vice versa. The effect appears insignificant (0.009) and is substantially smaller than the symmetric effect (0.672) which is significantly positive. Results show that there is no strong indication for a leverage effect. Therefore the data does not support this asymmetric supposition by specifying a non-linear GARCH model that allows for asymmetric shocks to volatility. Thus despite a slightly larger loglikelihood obtained by EGARCH model, GARCH is comparably a more appropriate model for our gas price return data. 
Table 8: ARMA(p,q)-EGARCH

\begin{tabular}{|c|c|c|}
\hline & $\begin{array}{c}\text { AR(2) } \\
\text { EGARCH(1,1) } \\
\text { b/se }\end{array}$ & $\begin{array}{c}\text { MAC(2) } \\
\text { EGACH }(1,1) \\
\mathrm{b} / \mathrm{se}\end{array}$ \\
\hline $\begin{array}{c}\text { ARCHM } \\
\text { sigma2ex }\end{array}$ & 0.000 & $-0.000^{* * *}$ \\
& -0.001 & 0.000 \\
\hline ARMA & & \\
L.ar & 0.118 & \\
& -0.073 & \\
L2.ar & $-0.147^{*}$ & \\
& -0.069 & \\
L.ma & & $0.110^{* * *}$ \\
& & -0.001 \\
L2.ma & & -0.131 \\
& & $()$. \\
\hline ARCH & & \\
L.earch & 0.010 & 0.009 \\
& -0.076 & -0.068 \\
L.earcha & $0.671^{* * *}$ & $0.672^{* * *}$ \\
& -0.153 & -0.094 \\
L.egarch & $0.876^{* * *}$ & $0.873^{* * *}$ \\
& -0.066 & -0.005 \\
cons & -0.571 & -0.588 \\
& -0.322 & $()$. \\
\hline 11(model $)$ & 397.7379 & 397.5245 \\
AIC & -779.4758 & -783.0490 \\
BIC & -748.2985 & -759.6660 \\
\hline
\end{tabular}

